\title{
EL PUEBLO TRABAJADOR VASCO. BREVE HISTORIA DE LA FORMACIÓN DE UN CONCEPTO Y SUS CONSECUENCIAS ESTRATÉGICAS EN ETA*
}

\author{
"Basque Working People». The Formation of a Concept \\ and its Consequences in ETA's Strategy
}

\begin{abstract}
Adrián Almeida Díez
Universidad del País Vasco/Euskal Herriko Unibertsitatea. España adrian.almeida@ehu.eus | https://orcid.org/0000-0002-2552-9766
\end{abstract}

Fecha de recepción: 01/06/2021

Fecha de aceptación: 17/09/2021

Acceso anticipado: 27/01/2022

Resumen: Las siguientes páginas estudian a partir de un enfoque interpretativo la formación histórica del concepto del Pueblo Trabajador Vasco en la organización ETA. Para ello desarrollamos un análisis que va desde el estudio de los imaginarios de las primeras juventudes nacionalistas vascas durante los años 40 a la ideología oficial de este colectivo armado en la década de los 60. Las fuentes utilizadas han sido fundamentalmente las publicaciones periódicas de estas agrupaciones (boletines como Beti Gazte!, Zabaldu, Kemen o Zutik) así como distintas obras ajenas a ellas, pero relevantes para la formación de su corpus doctrinal (por ejemplo, el libro de Federico Krutwig, Vasconia). A partir del análisis de la historia formativa del concepto de Pueblo Trabajador Vasco como sujeto al que apelaba ETA, hemos conseguido realizar una relectura de la estrategia desarrollada por este grupo desde su nacimiento y hasta el desarrollo de su Quinta Asamblea entre los años 1966-1967. De modo tentativo,

* Este artículo ha financiado a través del programa para la Formación del Profesorado Universitario (Referencia: FPU17/00816) y forma parte del proyecto de investigación subvencionado por el Ministerio de Ciencia, Innovación y Universidades PGC2018-094133-B-100 (MCIU/AEI/FEDER,UE), en el marco de un Grupo de Investigación de la Universidad del País Vasco/Euskal Herriko Unibertsitatea (ref. GIU 20/002). 
hemos descrito el uso de la violencia por parte de ETA como una estrategia constatativa. Es decir, su uso se orientaba a hacer visible el concepto subjetivo concebido por el colectivo armado como el reverso de todo lo afirmado en el régimen franquista. De forma paralela, las secciones no armadas de la organización se determinaron por realizar el proyecto político de ETA, la independencia y el socialismo del País Vasco, tratando de extender esa alternativa política entre la población.

Palabras clave: Nacionalismo vasco; ETA; violencia política; Pueblo Trabajador Vasco.

Abstract: From a philosophical standpoint, this article analyses the historical formation of the concept of the "Basque Working People» in the Basque armed organization ETA (Basque Country and Freedom, for its acronym in Basque). To accomplish this, we will study the imaginaries of the Basque Nationalists Youths during the 1940s and the official ideology of ETA in the 1960s. We have used primarily the ideological periodicals (journals such as Beti Gazte, Zabaldu, Kemen or Zutik) of these collectives as well as other relevant books (for example Federico Krutwig's Vasconia) and documents which helped in the formation of ETA's imaginary. Considering this historical formation of the concept of the "Basque Working People», we have reinterpreted the strategic approach of the organization since 1959. Tentatively, we have affirmed that ETA adopted a very specific use of violent methods, which were specifically oriented not to reach the goal of an independent and socialist Basque Country, but in the idea of making visible the concept of the "Basque Working People» in social reality. Thus, we have described this use of political violence as constative (and not performative). The non-violent strategic approaches of ETA were precisely focused on social spreading and implementation of its alternative imaginary: the achievement of independent and socialist Basque Country.

Keywords: Basque Nationalism; ETA; Political Violence; Basque Working People.

Sumario: 1. Introducción; 2. Apunte sobre el concepto, el sujeto y el dolor en Theodor W. Adorno; 3. Breve genealogía de la formación del concepto pueblo trabajador vasco en ETA; 4. Dolor, negatividad y praxis. La estrategia de ETA; 5 . Conclusión; 6 . Referencias bibliográficas.

\section{INTRODUCCIÓN}

Generalmente, el estudio de la organización ETA se ha centrado en analizar aspectos policiales, militares e ideológicos. Descubrir de dónde adquirían las armas los miembros de ETA, cuál era la estructura organizativa del colectivo, señalar cuáles eran las diferencias entre ETA-Quinta y ETA-Sexta o calibrar el grado de voluntariedad del uso de la violencia por esta organización política armada han resultado las cuestiones de mayor interés para los especialistas en esta organización armada (Domínguez Iribarren, 1998).

Aún son relativamente pocos los investigadores sobre ETA que centran sus estudios bajo enfoques filosóficos o antropológicos - los casos quizás más destacables de este último campo de estudio son las obras de Joseba Zulaika y Juan 
Aranzadi (1990; 2007; 2001). Desde el ámbito historiográfico, puede decirse que las investigaciones sobre ETA están copadas fuertemente aún por corrientes que se hallan bajo orientaciones adscritas a las corrientes del funcionalismo o la elección racional (González Calleja, 2016) ${ }^{1}$. Este hecho, evidente en buena parte de las obras recientes sobre esta organización (Fernández Soldevilla, 2016; Montero, 2018), limita de manera exponencial la posibilidad de una lectura de mayor alcance y de abrir nuevas vías aún inexploradas en el ámbito historiográfico vasco, recurriendo tan solo, y en contrapartida de la falta de novedad metodológica, a refrescar ciertos tópicos antiguos bajo miradas aparentemente novedosas. El recurso a los lugares comunes sobre los orígenes y desarrollos de ETA, descrita como una organización heredera de la cultura política del nacionalismo vasco más radical (sabiniano, racista y potencialmente violento $)^{2}$, resulta no solo una vía de explicación manida o

${ }^{1}$ A decir de Joseba Zulaika, escribir sobre terrorismo puede ser además «una actividad peligrosa. El tabú del objeto de estudio tiende a trasmitirse al texto escrito, que se convierte así simultáneamente en labor policiaca y apología del terrorismo» (Zulaika, 1991, pp. 217- 230).

2 Gaizka Fernández ha incluido al nacionalismo de la izquierda abertzale dentro de la categoría de nacionalismo vasco radical, en contraposición a otras culturas políticas nacionalistas como la moderada o la heterodoxa (siguiendo aquí el clásico esquema de José Luis de la Granja). El autor prueba muy brillantemente la falta de conexión personal y doctrinal de ETA con otros grupos de este sector aparecidos con anterioridad (los casos de Aberri, Euzko Mendigoxale Batza fundamentalmente), pero los considera, a mi juicio de forma poco matizada, coincidentes en la línea ideológica nacionalista radical y puristas en lo referido a la defensa de los principios del primer Sabino Arana. Conviene incluso añadir que la primera ETA fue menos audaz que el principal promotor de aquellas corrientes anteriores descritas como puristas. Así, por ejemplo, ETA recaló solo en los años 60 a los principios del antiimperialismo que ya había puesto encima de la mesa Elias Gallastegi en los años treinta en las páginas del semanario Jagi-Jagi. Sin embargo, una vez asumidos por ETA, estos principios, en la estela de los movimientos descolonizadores, adquirieron una significación social-revolucionaria que no estaba presente en las tendencias que habitualmente son insertas dentro del concepto de nacionalismo radical (ello a pesar de sus avances en materia de la cuestión social). Por otra parte, cabe destacar, de asumir tal clasificación, el abordaje de otras tendencias como la del sindicato nacionalista ELA-STV que asumió a partir de 1919 el principio de la unidad de la clase obrera frente a la «solidaridad de raza» o ANV, que aprobó en 1936 un proyecto inequívocamente de izquierdas que llevaron a la formación a mantener contactos y coaliciones con otras formaciones de izquierda a nivel español. Este último hecho ha derivado en la consideración de que ANV por ejemplo formaba parte de un nacionalismo heterodoxo, ya que no excluía el pacto con formaciones "españolas» como habrían hecho los grupos «radicales». No obstante, los grupos y colectivos de la izquierda abertzale, habitualmente descritos como partes del movimiento del «nacionalismo radical», tampoco lo hicieron (la Asamblea Popular Vasca, Euskadiko Ezkerra -en un principio integrada por los partidos abertzales de EIA, LAIA-Bai y EHAS, y el partido de izquierda EMK, que formaba parte del Movimiento Comunista de España-, la Mesa de San Francisco o la coalición Auzolan son buenos ejemplos de esta colaboración entre la izquierda abertzale y radical, que a nivel de base fue posiblemente aún más frecuente, porosa e híbrida debido a la participación de los militantes de uno y otro movimiento social de una misma escena social - bares, cuadrillas, 
recurrente $-y$ por supuesto también criticable-, sino potencialmente infructuosa para entender, por ejemplo, ciertas realidades presentes en la organización que requieren de enfoques más teóricos y críticos (que pueden proyectarse desde la antropología, la filosofía o nuevas corrientes de la sociología) ${ }^{3}$. Es justo desde este fundamento teórico y crítico desde donde los conocidos como Critical Terrorism Studies (conocidos como CTS) plantean su aproximación al fenómeno del terrorismo dentro del estudio de las relaciones internacionales contemporáneas (Jackson, 2016). Desde estos prismas, aún probablemente poco trabajados entre los historiadores de ETA (con notabilísimas excepciones como son las obras de los ya citados Zulaika o Aranzadi, o Alfonso Pérez-Agote, Ander Gurrutxaga, Benjamin Tejerina, Francis Jaúreguiberry, Jesús María Casquete o Ludger Mees) (Pérez-Agote, 2008; Gurrutxaga, 2003; Tejerina, 2015, pp. 1-19; Jauréguiberry, 2007; Aranzadi, 1994, pp. 189-208; Casquete, 2009; Mees, 2004) habrá de lograrse, en reproducción del alcance teórico de los CTS, una historiografía crítica del terrorismo que pluralice perspectivas teóricas (que haga uso de los preceptos de la Teoría Crítica, la teoría feminista, el post-estrucuralismo o la teoría de los movimientos sociales) y enri-

locales okupados, conciertos, lenguajes, referencias cultural-intelectuales, etc.). Quizás, como ha indicado Îñigo Bulliáin, debiéramos, si es necesaria una clasificación conceptual alternativa a la de izquierda abertzale, sin apostar por la en exceso abstracta, y, por tanto, inexacta de "nacionalismo radical», denominar a este movimiento como "revolucionarismo patriótico». En palabras de este autor: «Durante años la violencia se ha presentado como expresión de un nacionalismo radicalizado (...) por diversos motivos, se ha preferido calificar la violencia como terrorismo nacionalista, y acusarla de fascista o de nazi (...) e ignorar su perfil antisistema (...). Se ha propagado que como el revolucionarismo vasco es abertzale, su patriotismo es simplemente nacionalista». La violencia descrita como nacionalista y el movimiento que la utiliza como medio de acción política se convierten, por tanto, y bajo tales clasificaciones, en meras reproducciones de los viejos fascismos (Fernández Soldevilla, 2017; Mees, 1990; Mees, 1992; Elorza, 1978, p. 383; De la Granja, 1984; Bullain, 2011, pp. 15-16; Jagi-Jagi (2 de septiembre de1933), (número 47); Jagi-Jagi (25 de enero de 1936), (número 86).

${ }^{3}$ Gaizka Fernández, Raúl López Romo o Antonio Rivera han afirmado recientemente que ETA llegó a recuperar el componente racista del primer nacionalismo vasco. Amoldado a los nuevos tiempos, el antiespañolismo y antimaketismo sabiniano se habrían tan solo suavizado: los inmigrantes, el Otro de fuera, podría obtener naturaleza de vasco si se amoldaba a la identidad nacionalista y se asimilaba feliz a la cultura vasca. Esta afirmación, que podría tener sentido en la primera época de ETA, no sirve para describir el corpus doctrinal general de la organización, ya que a partir de la asunción, como veremos, del dolor como criterio general de adscripción étnica, quedaron antes bien excluidos de formar parte del Pueblo Trabajador Vasco no los obreros inmigrantes residentes en los territorios vascos, sino el empresariado de apellidos vascos (en casos culturalmente «integrado») y de larga raigambre en el territorio. Dentro de ese Pueblo Trabajador, inmigrado o no, podría haber gente con "conciencia nacional», que para ETA era el fundamento no de adscripción étnica, sino de adherencia con el planteamiento revolucionario que defendía y consideró, de manera radical, único válido (Fernández Soldevilla, López Romo, 2010; Fernández Soldevilla, López Romo, 2018; Rivera, 2018). 
quezca las explicaciones sobre los hondos impactos de la organización ETA sobre la sociedad vasca.

Uno de los aspectos que pretenden abordarse aquí, desde un punto pretendidamente teórico e interpretativo, es la relación entre el marco o imaginario de significado elaborado por ETA en referencia a la cuestión de la subjetividad y el desarrollo por parte de esta misma organización de una estrategia violenta/ y noviolenta específica de acuerdo a ese marco. Adoptamos así una de las propuestas metodológicas más actuales defendidas tanto por estudiosos asociados a los CTS como por distintos sociólogos analistas del fenómeno de la violencia política. Este planteamiento trata de poner en conexión la teoría de los movimientos sociales con el análisis concreto de los grupos practicantes de la lucha armada política (Beck y Schoon, 2019; Gunning, 2009). De manera específica, y como decíamos, utilizaremos el análisis de marcos (o framing analisys), dentro de esta teoría general, para explicar la formación conceptual por parte de ETA del sujeto político objeto de su lucha (el Pueblo Trabajador Vasco), así como para comprender la adopción de unas formas concretas de acción política por parte de la organización vasca.

La escuela del framing, que propone el estudio de los marcos/imaginarios para explicar la formación y desarrollo de la acción colectiva, se encuentra, de forma paralela, relacionada con dos escuelas historiográficas importantes con las que enlazaremos, asistemáticamente, nuestra propuesta de análisis. Estos enfoques son la historia postsocial y la historia conceptual. Ambas corrientes historiográficas, críticas con la historia social y cultural más clásicas, se encuentran, a su vez, mutuamente interconectadas en su invitación a interpretar y esclarecer la significación lingüística de la realidad social producida por los distintos actores como elemento sustancial de cara a lograr comprender los distintos fenómenos históricos protagonizados por dichos actores. Dentro del acercamiento interpretativo general al marco de significado producido por ETA proponemos leer la elevación del concepto subjetivo, del actor social descrito como referente para su actividad política, desde el enfoque filosófico del pensador de la primera Escuela de Frankfurt, Theodor W. Adorno. Sostenemos que esta lectura concreta, dentro de la explicación de la formación histórica de este concepto, permitirá interpretar mejor los usos otorgados a la violencia política, así como razonar, dentro del análisis de marcos, las otras estrategias no armadas llevadas a cabo por parte del colectivo tomado como objeto estudio (Rivas, 1998; Koselleck, 1993; Cabrera, 2007, pp. 41-72; Rigby, 2011, pp. 95-114). Comenzaremos, por tanto, este breve texto explicando, muy resumidamente, el pensamiento de Theodor W. Adorno, para, posteriormente, valernos de su aproximación filosófica en nuestra interpretación específica del marco de significado que, en relación al concepto subjetivo del Pueblo Trabajador Vasco, realizó la organización ETA. 


\section{APUNTE SOBRE EL CONCEPTO, EL SUJETO Y EL DOLOR EN THEODOR W. ADORNO}

Thedoro W. Adorno, afamado pensador alemán de la Escuela de Frankfurt, realizó dos obras fundamentales del pensamiento crítico contemporáneo como fueron la Dialéctica de la llustración (firmada junto con su amigo, el también filósofo, Max Horkheimer en 1944) y la Dialéctica Negativa, publicada a finales de los años 60. Adorno se propuso a través de ellas realizar una honda crítica a la modernidad y a la elevación, a partir de ella, de un modo de pensamiento estructurado a partir de una razón de tipo instrumental o pragmática. Aquella razón, que habría tenido por objetivo el dominio de la naturaleza, la superación del mito para lograr la autoconservación, habría acabado por dominar la naturaleza al interior de los propios individuos, condenando a la irracionalidad, al barbarismo, cualquier manifestación no asociada al objetivo de la autoconservación dentro del sistema político, económico y social establecido. De este modo, en opinión de Adorno (y de su colega Max Horkheimer), la razón estructuradora de la modernidad desde la llustración se habría transformado en el mito que decía querer superar, siendo su epítome históricamente concreto el nacionalsocialismo y el fascismo ( $y$, en cierta forma, podría decirse también que el franquismo en España). Bajo tal movimiento político de la primera mitad del siglo xx se habría activado, en aprovechamiento de la reacción popular contra el racionalismo y la tecnificación de la vida bajo la modernidad capitalista, la necesidad del retorno a la naturaleza, a la autenticidad de la existencia (por usar la terminología propiamente heideggeriana), tan solo para aplicar la racionalidad más inclemente (Adorno, Horkheimer, 2016, pp. 44-50; Stone, 2014; Horkheimer, 2010, pp.136-137; Faye, 2018, pp. 54-55). Adorno implementó, desde esta posición, una crítica contra la conversión de esta razón en mito, efectuando para ello una recomposición de la teoría filosófica del que consideró proyectista de este resultado, Georg W. Hegel y en ataque al falso escapista del mismo, Martin Heidegger. En el reproche a Hegel, Adorno estimó que la lógica dialéctica de Hegel, elevada a ontología (frente a las meras antinomias epistemológicas de Kant), encerraba, abstraía, en su reconciliación, la pluralidad de manifestaciones sensibles del objeto a la identidad ideal del concepto. Este pensamiento identificante tenía, más allá de su descripción como proceso de clasificatorio y reduccionista del conocimiento, una proyección concreta en la secuencia de la historia de la modernidad. A partir de este principio dialéctico que reconciliaba las diferencias en un todo superior, se daba pie a la eliminación práctica de la diferencia social. Bajo la concepción hegeliana de la dialéctica del proceso racional como ontología, aquellos que rebasaban el concepto emergido pasaban a ser así, en la resolución del antagonismo, exterminables (Hernández-Pacheco, 1992, p. 90; Rose, 1978, p. 44; Stone, 2014; Adorno, 2005). Bajo este prisma denunciante de Hegel, no compartido, por ejemplo, por Slavoj Žižek o fuertemente criticado por Carlos Pérez Soto, se elevaba, por tanto, y 
en opinión de Adorno, un sujeto sometido, subsumido y adaptado para el logro de la autoconservación (reprimiendo la manifestación de sus diferencias para evitar la muerte), a la lógica identificante del sistema establecido. La constitución subjetiva de la modernidad se hallaría en consecuencia determinada por el sufrimiento, por el dolor, por el desgarro que suponía una renuncia que era, al tiempo, el reverso el sometimiento a la identidad ideal (Žižek, 2003; Pérez Soto, 2005; Pérez Soto, 2009).

Desde ese plano del dolor y del desgarro se abriría, para Adorno, la condición de pensar de una forma no-identitaria. Es decir, el objetivo de su dialéctica se basaría en la pretensión de captar la fuerza que rebasa y contradice el concepto en su aspiración de universalidad. El dolor, el sufrimiento en la sociedad moderna, la angustia cotidiana, es un elemento de elocuencia para aspirar a la verdad. A partir de él se logra testificar materialmente, así, la falsedad del sistema establecido en su pretensión de afirmación total de la identidad: «el dolor [en Adorno] representa un correctivo frente a la filosofía de la identidad, pues expresa sus grietas y fracturas; es decir aquella dimensión de la experiencia que se resiste a ser clasificada. Pero la expresión del dolor lo es también de lo corporal y lo natural siempre oprimido» (Escuela Cruz, 2017, pp. 181-196).

El pensamiento debería aspirar así, en su reformulación no-identitaria, a una nueva forma de conceptuación marcada por el respeto a la multiplicidad de relaciones y significaciones del objeto. Debería, en definitiva, aspirar a traducir el dolor lingüísticamente. Es decir, tendría que ambicionar captar conceptualmente justamente «lo que el concepto ha amputado en el interior» de la cosa. A esta confección del pensamiento, Adorno la denominó como «constelación», como «el momento unificador» en que sobrevive «la negación sin negación» (Adorno, 2005, pp. 156-157; Bonefeld, 2007, pp. 133-136; Buck-Morss, 1981, p. 193; Cabot, 1999, pp. 33-48; Cabot, 2007, p. 85; Hernández-Pacheco, 1996, pp. 95-96; Schwarzböck, 2008 , pp. 51 y 258). La «constelación» se refiere aquí a un contexto y no a un ejercicio de identificación, adquiriendo su entera vigencia en la contingencia histórica y en la determinación de las relaciones y significaciones reales de vida (Adorno, 1966/2005, p. 157; Cabot, 1999, pp. 33-48; Gregori Brull, 2007, p. 28). A decir de Mateu Cabot (2007, p. 85), en las constelaciones adornianas «los conceptos [yuxtapuestos] se agolpan alrededor de un objeto central tratando de aprehenderlo sin someterlo bajo una sola categoría y poniendo los conceptos no al servicio de los puros fines operativos e instrumentales del sujeto, sino buscando lo que hay de verdad en la cosa sin catalogarla como si fuera puro dato".

Bajo este sucinto y simplificado resumen a la filosofía de Adorno, planteamos comprender el concepto subjetivo elaborado por ETA en 1967, denominado como Pueblo Trabajador Vasco, como una traducción lingüística del dolor provocado por la pretensión totalitaria del régimen franquista. Desde esta lectura particular, consideraremos que la organización vasca replanteó la identidad vasca como una noidentidad dentro del franquismo. A partir de este marco de significado, ETA logró 
conceptuar una nueva subjetividad denominada como Pueblo Trabajador Vasco. De esta forma, la organización habría repensado los vínculos teóricos existencialistas del primer nacionalismo vasco hacia una posición dialéctica, obteniendo, a partir de este fundamento, una idea concreta sobre el ejercicio de la violencia, que se orientaría hacia la constatación del dolor colectivo a partir de la provocación de la respuesta violenta del régimen franquista contra los habitantes de los territorios vascos.

\section{BReVe genealogía de la fORMACión del CONCEPto PUEblo TRABAJADOR VASCO EN ETA}

El concepto de Pueblo Trabajador Vasco fue asumido por la organización ETA en su Quinta Asamblea (celebrada entre 1966 y 1967). El término ha sido, aunque no de manera amplia o sistemática, objeto de estudio por parte de diversos investigadores. Autores como el antropólogo Juan Aranzadi (1981, p. 31) o el historiador Gaizka Fernández (2019, p. 316) han advertido, así, que el concepto se determinó, en la nueva narrativa etarra, y tras aquella asamblea, por su carácter bifronte ${ }^{4}$. El concepto se elevaba como compendio de los dos sujetos a liberar a partir del socialismo y el nacionalismo: respectivamente el trabajador y el pueblo vasco. El marco de significado de ETA concibió, dentro de esa forma múltiple que caracterizaba al sujeto concebido, un proyecto para la liberación de aquel actor de una forma marcadamente mesiánica. El retorno, la redención, la vuelta al origen auténtico, a la prehistoria de la sociedad vasca, a la esencia vasca perdida, eran, bajo la perspectiva de ambos autores, los objetivos últimos de ETA tras la Quinta Asamblea que alumbró tal principio del Pueblo Trabajador Vasco. En puridad, este fundamento mesiánico, sin una lectura oportuna que concrete su especificidad dentro del marco elaborado por ETA, ha acabado, bajo tal interpretación, por quedar subsumido bajo una indistinción con respecto al primer nacionalismo del fundador del nacionalismo vasco, Sabino Arana. El hecho de que el nuevo nacionalismo vasco emergido por el imaginario de ETA sea simplemente calificado por un amplio número de autores como «nacionalismo vasco radical» invita justamente a colegir que es precisamente esa la pretensión: la de observar en el marco de significado de ETA una renovación del fundamento del retraimiento histórico demandado por Arana para hacer frente a la modernidad durante el siglo xIX (Fernández Soldevilla, López Romo, 2010). Contrariamente a esta lectura, creemos necesario trazar una aproximación a la formación de este concepto, que resalte su novedad y sus implicaciones.

4 Juan Aranzadi (2001, p. 67) calificó de "engendro» a este concepto en su Escudo de Arquíloco. Sobre mesías, mártires y terroristas. Sangre vasca. 
La emergencia de la categoría del PTV en la Quinta Asamblea debe en parte sus orígenes a la obra del pensador y filólogo vasco-germano Federico Krutwig, Vasconia (de 1963), la cual, aunque no ha sido ampliamente destacado, llevó el subtítulo elocuente y bastante pretencioso de «estudio dialéctico de una nacionalidad». Esta obra, que fue propagandísticamente titulada por la prensa franquista como «la biblia de ETA», facilitando así irónicamente su difusión entre la disidencia nacionalista

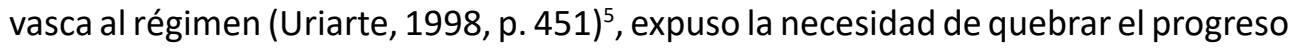
iniciado con la modernidad, que, a su entender, habría supuesto la descomposición de la «naturaleza vasca» imponiendo un «orden jurídico extraño» (Krutwig, 2006, p. 281). Si bien al igual que el fundador del nacionalismo vasco, Krutwig atacaba a la modernidad, su objetivo, en concomitancia de los postulados de la primera Escuela de Frankfurt, no fue tanto el de concluir un retraimiento histórico para recuperar la esencia vasca perdida (como pretendió el nacionalismo fascista), sino situar lo vasco como una negatividad antagónica dentro de la modernidad capitalista. Es decir, con Krutwig comenzó a elevarse un imaginario dentro del nacionalismo vasco que infería "lo vasco» como un negativo de la sociedad afirmada a partir del triunfo de la modernidad y el progreso en los estados español y francés (2006, p. 205). Interpretado desde la formulación adorniana referida, la irrupción de la modernidad en los territorios vascos significaría consiguientemente la puerta de entrada para la constitución de la subjetividad cosificada de la modernidad en aquellos territorios. Desde este plano, la negación de la «naturaleza» de lo vasco fue significada como un desgarro doloso consustancial a la formación del sujeto amoldado a la identidad ideal del concepto. La cultura vasca, reducida en el devenir de la modernidad a ser un elemento barbárico, ajeno al imperativo de la razón instrumental, se habría instituido así en el remanente utópico liquidado de un pasado que podría haber dado como resultado una historia diferente (sin opresión nacional ni clases). La lengua vasca, por ejemplo, como ruina de un pasado nunca fructificado, se proyectaría efectivamente como una imagen dialéctica, dado que confrontaría, en su mero uso presente, con la realidad afirmada que lo niega. Bajo nuestra interpretación, por tanto, el objetivo de Krutwig, no fue tanto negar el progreso para volver al pasado, sino confrontar dialécticamente los resultados del mismo rompiendo su continuidad (Krutwig, 2006, pp. 81-435; Joas y Knöbl, 2016, p. 148; Benjamin, 2004). Desde este punto de vista, la apelación de Krutwig al pasado, que se insertará en el nuevo marco de significado etarra, no sería exactamente de oposición a la modernidad para el logro de una Edad de Oro en donde retornar a la esencia de lo vasco; al mundo rural idealizado apelado por el primer nacionalismo vasco. La suya sería una apelación que buscaría confrontar la realidad social presente del franquismo como culminación del dolor de la modernidad (iniciado con una llustración denunciada

${ }^{5}$ Muga (septiembre de 1979). Ayer y hoy de Federico Krutwig. (Número 2). Bilbao: Iparragirre. 
por Krutwig de forma explícita), con la aplicación de las esperanzas no realizadas del pasado (la utopía nunca alcanzada): «no nos podemos oponer al devenir histórico, aunque sí tenemos que ajustarnos a él con nuestra idiosincrasia nacional». La idea del franquismo como culminación de una etapa dolorosa, como la Pasión que antecede a la completa Resurrección de la patria vasca, había sido, como explicitaban las hojas de la publicación nacionalista vasca clandestina del Espetxean (redactada por presos nacionalistas vascos durante los primeros momentos de su encarcelamiento tras su derrota en 1937 frente a la sublevación franquista) una imagen recurrente entre el nacionalismo vasco de finales de los años 30 (Krutwig, 2006, p. 81; Benjamin, 2004, p. 465; Löwy y Varikas, 2007, p. 99; Almeida Díez, 2020, pp. 119-142)6. Esta idea del aplastamiento del mundo moderno, del sufrimiento de él devenido entre los habitantes vascos, y cuyo corolario se realizaría en el franquismo y su afán civilizador para con las diferencias culturales en el Estado Español, se trasladaría enteramente a ETA. La concreción política de esta lucha contra el significado poder civilizador se realizó en torno al precepto antiimperialista que pudo hacerse viable como imaginario dada la presencia misma de aquella dictadura de Franco. Como denunciaron Horkheimer o Adorno al hablar del nacionalsocialismo, autores como Zira Box, José Carlos Mainer, Miguel Ángel Jiménez Martínez, Ismael Sanz o David Marcilhacy han advertido precisamente que, en mimética reproducción de aquel movimiento ultraderechista alemán, el franquismo reunía en sí las apelaciones a la tradición (incluidos los fueros de los territorios vascos defendidos por los carlistas sublevados), la reacción frente a la modernidad, el mito de la España pre-moderna y monárquica, con la idea del imperio y de la unidad de la patria «en su destino universal» como el todo que, bajo la impresión orteguiana, diluiría, «incorporaría», la divergencia nacional, regional, y de clase (Box, 2013; Mainer, 2015; Jiménez Martínez, 2015; Saz, 2003; Marcilhacy, 2014, p. 77; Bastida Freixedo, 1997). Desde este prisma, la apelación antimodernista de Krutwig, la apelación al excedente utópico liquidado del pasado vasco para el logro de una sociedad emancipada y sin clases, elevó un imaginario que proyectaba, al menos teóricamente, un futuro de libertad para todos aquellos que sentían el dolor de aquella modernidad. En este sentido, la clase trabajadora inmigrada en los territorios vascos como consecuencia de la instalación de la modernidad capitalista en el Estado español no sería vista, en adelante, como el fundamento del rechazo a aquel proceso histórico (como ocurría a partir de la demanda «antimaketa» de la primera doctrina nacionalista de Arana), sino, y en concomitancia a la divergencia cultural vasca en la formación de ese mismo Estado, parte de una negatividad antagónica. Es decir, la clase trabajadora sería parte constitutiva de un nosotros que se resistía a encerrarse a la abstracción, al reduccionismo conceptual de aspiración universal propuesto bajo el franquismo. Krutwig, por

${ }^{6}$ Espetxean (11 de octubre de 1937). Del Presente. Juventud, rebeldía=Patria. (Número 1). Dueso-Santoña: presos nacionalistas vascos. 
tanto, logró aglutinar en su obra la percepción desarrollada dentro de las juventudes nacionalistas vascas durante los años 40 y 50 de que los asalariados inmigrantes eran parte del bando de las víctimas de aquel proceso y no los victimarios de la idiosincrasia vasca. Desde este punto a partir del que Krutwig acabó por re-significar la identidad vasca desde todo aquello que no cabía en el sistema establecido, aquellas juventudes aspiraron a insertar el nacionalismo dentro de unas coordenadas nítidamente sociales, llegando, en casos, a la crítica abierta al capitalismo (Jauréguiberry, 1983, p. 179; Krutwig, 2006, pp. 108-109; Letamendia, 1994, p. 288; Dussel, 1994).

Durante aquellas dos décadas de los años 40 y 50, pequeños colectivos de jóvenes nacionalistas surgidos en el interior del País Vasco de forma clandestina como, por ejemplo, Beti Gazte! (Siempre joven), habían declarado de forma clara aspirar a cambiar «las formas económicas presentes» en la futura patria vasca liberada ${ }^{7}$. Para el grupo de estudiantes nacionalistas de EIA (Eusko Ikasle Alkartasuna - Solidaridad de Estudiantes Vascos), formado en 1942, y en donde trabajaría el futuro fundador del grupo Ekin del que surgiría la organización ETA en 1959, José Luis Álvarez Enparantza, Txillardegi, la justicia social era parte de la tradición del pueblo vasco ${ }^{8}$. En el colectivo juvenil que editaría el boletín Eutsi! (Resiste), el cual comenzó su singladura en 1949 bajo el apoyo del PNV de Donostia, expresó la necesidad de transformar el capitalismo «para conceder al trabajo, al trabajador el rango que corresponde en justicia a la más honrosa de las actividades del hombre» (Barandiaran, s. f., p. 116) En 1952, los miembros de Eutsi! gritaban la consigna de «por la libertad vasca y la justicia social: Gora Euzkadi Askatuta! ${ }^{10}$. De hecho, el propio boletín oficial de las juventudes del PNV en el interior (EGI), el Azkatasuna (que antes había pertenecido a EIA), propuso en enero de 1946 la abolición del proletariado como producto de un régimen inhumano llamado capitalismo (De Pablo, et al., 2001, p. 188) ${ }^{11}$.

A fines de la década de los 50, y alrededor de EGI, surgieron también otros grupúsculos juveniles que editaban pequeños boletines como Zabaldu (Extender) o Kemen (Fuerza/Vigor). Más tarde recalarían en Ekin y sus manchetas se convertirían en las de la futura ETA. Concretamente el Kemen se convirtió en el boletín interior del futuro colectivo armado. En estos grupos no solo comenzó a denunciarse la represión policial franquista contra los procesos huelguísticos de Asturias y Guipúzcoa durante el período, o a reclamar una subida salarial para dignificar la vida

7 Beti Gazte (enero de 1947). Invitación a la juventud. (Número 1). Sin lugar conocido: jóvenes nacionalistas vascos.

8 Ikasle (curso 48/49). Objetivos de EIA. (número 1). Bilbao: EIA.

9 Eutsi (octubre de 1950). Y de los patronos..., qué? (Número 12). Donostia: jóvenes nacionalistas vascos.

${ }^{10}$ Eutsi (1952). A la juventud vasca, nuestra esperanza. (Número 53). Donostia: jóvenes nacionalistas vascos.

${ }^{11}$ Azkatasuna (enero de 1946). Declaración de principios. Euskadi: Ediciones EIA. 
de los trabajadores, sino a ejemplificar modelos de acción como el del movimiento anticolonialista argelino (la guerra de independencia en el país norteafricano contra la República Francesa se inició oficialmente en 1954, con la ofensiva militar de la guerrilla del Frente de Liberación Nacional) ${ }^{12}$. El cierto giro social, siempre desde una actitud ciertamente paternalista antes que dialéctica, vino además reforzado entre las juventudes nacionalistas con la publicación del libro La Causa del Pueblo Vasco, escrito durante el exilio en 1956 por uno de los principales ideólogos del PNV, Francisco Javier de Landaburu, quien reprochó a los patronos nacionalistas vascos el querer una patria liberada asentada sobre la misma paz social impuesta a golpes por el franquismo (Watson, 2007, p. 195; Garmendia, González Portilla, 1993, pp. 194-195). Este momento paternalista se expresó también, por ejemplo, en uno de los primeros textos teóricos de ETA como fue el Libro Blanco, redactado en 1960. En esta publicación, como destacaron John Sullivan (1988, p. 41) o Gurutz Jaúregui (1981, pp. 97-98), ETA se refirió a la cuestión social de un modo marcadamente cristiano-demócrata, viendo aún en la inmigración un problema para la manutención de rasgos comunitarios vascos. A decir de Joseba Zulaika (2007, p. 28): «los pilares del nuevo patriotismo de ETA [a partir de aquellos años] eran: la decisión irrevocable ignaciana (...); la libertad absoluta sartriana (...); y el juramento sabiniano de ofrecer la vida por la patria». Durante esta época, y contrariamente a las posteriores consideraciones de Krutwig, la defensa de lo vasco en ETA era comprendida en exclusiva como una lucha por su vivificación frente a su extinción programada por el franquismo. Es decir, hasta las formulaciones de aquel autor, la identidad vasca debía ser simplemente recuperada, salvada de su desaparición forzosa. Esta no representaba aún una negatividad antagónica dentro del franquismo o dentro del mismo proceso formativo del moderno Estado nacional español. De igual manera, la cuestión social se resolvió, durante este primer período, bajo una mirada reformista, que excluyó cualquier principio dialéctico, al considerar a este parte de una doctrina marxista de la que el nacionalismo vasco aún se consideraba ajeno (Equipo Hordago 1, 1979, pp. 276-277). En los propios cuadernos de formación de la primera ETA, el estudio de la dialéctica se retraía a su relación con el marxismo, advirtiendo de forma paralela que la única tarea de un nacionalista era "salvar lo vasco» $y$ «hacer la resistencia» ${ }^{13}$.

En los Principios de la organización, asumidos a partir de la realización de la Primera Asamblea (en mayo de 1962), se mantuvo la importancia principal en

12 Kemen (EGI) (octubre de 1958): Trabajo y salario e Infiltración del fichado en una organización religioso-recreativa. (S.n.). Interior: militantes de Euzko Gaztedi.; Zabaldu (marzo de 1958). Sin título. (S.n.). Noticiario de Eusko Gaztedi; Interior: militantes de Euzko Gaztedi; Zabaldu (¿1958?). La huelga de Guipúzcoa. (S. n.). Noticiario de Eusko Gaztedi.

13 ETA (1962). Cuadernos de Formación de ETA. http://www.ehk.eus/es/ii-asambleacast/509-documentos-ii-asamblea-cast/4258-cuadernos-de-formacion-de-eta-cast [Fecha de consulta: 14/09/2021]. 
palingenesia de lo vasco, sin relacionarse aún con el programa de acción social (que, sin embargo, había ganado terreno). En agosto de 1962, Txillardegi expuso ya que los patronos eran enemigos de Euskadi, aunque estos se expresaran en euskera ${ }^{14}$. A decir de Gurutz Jaúregui (1981, p. 171) y José Antonio Garmendia (1979, pp. 71-72), el inicio del trabajo de agitación en el ámbito obrero por parte de ETA llevó a una transición en la propia lógica de la organización que derivó progresivamente, con la plasmación teórica a partir de Krutwig, en el «establecimiento de una relación de causa entre la opresión franquista y la opresión puramente española y la precaria situación de los trabajadores», en gran medida inmigrantes.

En ETA, por tanto, antes de que la obra de Krutwig tuviera un cierto impacto en la renovación de sus marcos de significado, fue la propia lucha de la clase trabajadora en las numerosas fábricas y talleres de la geografía vasca durante los años 60, y la propia inserción del colectivo en aquellos entornos, lo que motivó el giro progresivo hacia la consideración general de la lucha obrera y nacional vasca como parte de un todo que se remitía a una misma contradicción dentro de la modernidad capitalista. Ambos fenómenos comenzaron a visualizarse, por tanto, como una totalidad antagónica. Es decir, ambas problemáticas se insertaron como partes constituyentes de un mismo antagonismo estructural que recorría la dictadura franquista como consecuencia de su pretensión totalitaria. La lucha por la cultura vasca, por la mejora de las condiciones de vida de los trabajadores, comenzaría a ser una lucha contra la dictadura franquista, que pasó a ser, dentro del marco de significado de ETA, el problema a resolver. Con la extinción de este régimen político se esperaba lograr solventar las problemáticas nacionales y sociales. Podríamos decir, bajo nuestra lectura adorniana, que ETA se dio cuenta que el principio de identidad, el dolor que tal principio emergía entre los individuos de los territorios vascos, perpetuaba el antagonismo que el franquismo deseaba justamente reprimir allí. De esta evidencia, ETA extrajo progresivamente dos conclusiones mutuamente relacionadas: un concepto subjetivo que diera cuenta de forma universal de los particulares antagonismos y una estrategia armada que constatara el dolor como síntoma tanto de la pretensión totalitaria del régimen como de su imposibilidad (Adorno, 2005, p. 139; Adorno, 2017, p. 462; Martín, 2016).

Como ya describió Gurutz Jaúregui (1981) el giro más nítidamente obrerista de ETA, que se expresaría a partir de la renuncia a los análisis xenofóbicos de la cuestión inmigrante, comenzó a partir de la publicación del número 12 del boletín exterior de ETA, Zutik, y culminaría, muy posiblemente, con la publicación de la conocida como Carta de los Intelectuales. Justo en el Zutik número 11, la organización había llegado a afirmar cosas tales como que «la inmigración en Euzkadi, considerada ya como problema, tiene por causa la pérdida definitiva de su libertad» (Jauréguiberry,

${ }^{14}$ Zutik (agosto 1962). (Número 4). Boletín exterior de ETA. 
1983, p. 179; Equipo Hordago 2, 1979, pp. 352-353) ${ }^{15}$. Tras aquellas declaraciones, los inmigrantes, "los coreanos», "los maketos», dejaron de ser considerados algo así como los pied-noirs de la sufriente Euskadi, para comenzar a ser considerados víctimas de un sistema socioeconómico capitalista impuesto por el mismo poder político que destruía los rasgos comunitarios vascos (Avilés Farré, 2010, p. 16) ${ }^{16}$. En aquel boletín, ETA indicó lo siguiente:

se ha argumentado que la inmigración en nuestro país ha sido una maniobra política (...). Se trata de un fenómeno socioeconómico, y, por tanto no es una maniobra política. Para situar la cuestión en sus justos términos digamos que este fenómeno natural de inmigración interna dentro del Estado español ha venido como anillo al dedo a los intereses políticos del fascismo español (...), pero nosotros no podemos confundir los efectos con las causas, ni atribuir a la masa de <coreanos > ninguna colaboración con una maniobra que no existe en realidad (...). Por el contrario, los trabajadores españoles, son por razones diferentes, ciertamente las víctimas del desastre franquista ${ }^{17}$.

En el número 16 de la misma publicación de ETA en el que apareció por primera vez una reseña del libro de Krutwig a cargo de Txillardegi, se publicó un comentario similar, en el que se advertía muy significativamente que:

los inmigrantes no han contribuido a la pérdida del euskera (...). La causa de la pérdida del euskera es política y su solución será política también (...). Nuestro patriotismo es progresista, abierto, sin consideraciones raciales y sin admitir la opresión capitalista, aunque sean vascos los explotadores. Nuestra lucha es de liberación nacional y de revolución social ${ }^{18}$.

Desde mediados de los años 60, ETA, a partir de su experiencia en el campo obrero y el impacto de la propia obra de Krutwig, resignificó, por tanto, como parte de la comunidad del dolor a los inmigrantes de los territorios vascos, en la medida en que estos componían un importante grueso de la fuerza laboral asalariada. Este paso fue muy relevante para la aproximación conceptual a ese nuevo nosotros ya intuido por la organización y compuesto de todo aquello que no cabía o habitaba como contradicción en la modernidad capitalista. Como ha destacado Olaya Fernández Guerrero (2019, pp. 186), «el dolor nos duele, pero la experiencia del mis-

15 Zutik (abril de 1963). (Número 11). Boletín exterior de ETA.

${ }^{16}$ El propio Txillardegi advirtió en el Zutik 16 que los inmigrantes no eran los causantes de la pérdida del euskera, sino que esta pérdida se debía a una causa política (Equipo Hordago 2, 1979, p. 382).

17 Zutik (1963). Carta a un Coreano. (Número 12). Boletín exterior de ETA.

18 Ibid. 
mo no se reduce a un dato estrictamente personal y subjetivo, sino que también es posibilidad de encuentro con otros individuos...». El nacionalismo vasco emergido a partir de ETA renovó, por tanto, los imaginarios del conjunto de aquel movimiento a partir de ese encuentro en el dolor, proyectando, así, y aún sin la conceptuación consiguiente, una nueva identidad vasca - entendida como no-identidad- desde el todo negado. El mismo año 1963 en el que los militantes de ETA comenzaron una labor más comprometida en el ámbito obrero, un nuevo cuaderno de formación de la organización indicó elocuentemente que ETA luchaba contra «todas las opresiones» y para liberar a la "persona vasca» (Equipo Hordago 2, 1979, pp. 184-185). Ya no se trataba por tanto de luchar por vivificar lo vasco y de dignificar la vida del proletariado, sino de rechazar el "otro" que convertía los rasgos comunitarios vascos y al proletariado en su mismo negativo. De esta forma, a partir de la negación materializada como represión, ETA visualizó y centralizó su modelo de acción.

La Tercer Asamblea de la primavera de 1964 aprobó efectivamente el documento la Insurrección en Euskadi, que vino a ser una especie de corolario en la concepción partisana de ETA desde el precepto antiimperialista asumido a partir de Krutwig, el cual permitiría plantear la lucha desde el todo aquello que no cabía en el orden social establecido. A partir de este momento se produjo así una reformulación plenamente acorde con la asunción del movimiento dialéctico esbozado por Krutwig, exponiéndose, incluso, en Zutik posteriores, que el lema JEL (Dios y Ley Vieja), en su apelación al pasado no realizado, significaba esencialmente «socialismo vasco» (Equipo Hordago 3, 1979, p. 256).

A finales del año 1964, ETA reclamó el compromiso de los intelectuales vascos en una carta conocida como Carta a los Intelectuales en la que, sin llegar a conceptuar aún al sujeto de su proyecto político, se comprometió a entablar la misión de dar a conocer la totalidad de la realidad de opresión, afirmando así que la existencia de una dictadura facilitaba la posibilidad de generar un movimiento a partir de dicho dolor causado por la represión. La pretensión totalitaria y la visibilización de dicha pretensión darían cuenta, en opinión de ETA, de la misma falsedad del sistema. Tras la Cuarta Asamblea (verano de 1965), en la cual se admitió el documento de las Bases teóricas de la Guerra Revolucionaria que propició precisamente esa idea con la asunción del precepto de la acción-represión (volveremos sobre este tema en el siguiente apartado), algunos documentos de la organización mantuvieron la voluntad de seguir comprendiendo el plano de la problemática nacional desde la misma «naturaleza» opresiva que las relaciones de producción ${ }^{19}$. Sin embargo, el cada vez mayor protagonismo de la Oficina Política de ETA, imbuida en unas lógicas obreristas, Ilevó al colectivo a tantear la fijación de su concepción subjetiva exclusivamente en el proletariado. Es decir, para un grupo de militantes, liderados por Patxi Iturrioz, el nosotros subjetivo frente a las categorías de dominio del franquismo, se limitó,

${ }^{19}$ Ver por ejemplo el Zutik número 38. 
tras sus lecturas, al terreno conocido e históricamente escudriñable del marxismo. Entre el Zutik 41 a 44 de la organización, la Oficina Política apeló a la unidad de la clase obrera, al internacionalismo y a la necesaria consideración de Euskadi como diferencia nacional dentro del Estado.

Los sectores de ETA que habían construido y defendido la doctrina antiimperialista, como lucha contra la totalidad de las opresiones experimentadas por los habitantes en los territorios vascos, comprendieron entonces que la demarcación singularizada en la clase social destruía la visualización del elemento vasco como contradicción sistémica para convertirla simplemente en una lucha por la aceptación de la diferencia dentro de la multiplicidad cultural del Estado Español. En la primavera de 1966, Krutwig, vinculado ya a ETA, inició la ofensiva contra esta tendencia a partir de varias publicaciones en la revista Branka, que, fundada por Txillardegi en el País Vasco francés, aglutinó, desde aquella fecha, a toda la oposición al obrerismo en ETA (Agirre Odriozola, 2017). En el primer número de la publicación, de abril de 1966, Krutwig indicó a este respecto que «dado la forma en que se presenta en concreto la lucha de clases, bajo su aspecto de lucha nacional del pueblo oprimido contra el opresor, verdaderamente revolucionario sólo será quien reuna en sí ambos polos (...) de la contradiccion $"{ }^{20}$ Esto es, quien se opusiera a todas las opresiones provocadas por el régimen reaccionario franquista en el concreto territorio vasco (Letamendia, 1994, pp. 305-306; Pérez-Agote, 2018, p. 336; Jauregui, 1981, p. 304; Garmendia, 1979, p. 220). Para Krutwig, cualquiera que defendiera el concepto de España era sencillamente reaccionario por mucho que se presentara como progresista. Tal concepto «se encontraba representando en nuestra tierra [en Euskadi] la opresión nacional y social». ${ }^{21}$ De lo cual podríamos colegir que lo que Krutwig anhelaba describir es justamente la derivación reaccionaria de los presentados como progresistas españolistas (especialmente la del Partido Comunista de España) frente al progresismo real de los presentados como reaccionarios vasquistas (ETA y la corriente intelectual afín). El nacionalismo vasco que Krutwig defendía se presentó, así, como lo verdaderamente revolucionario frente a otras tendencias no nacionalistas vascas que, salvaguardando el concepto de España, automáticamente apostarían por suprimir o superar la expresión nacional concreta que la lucha de clases adoptaba en los territorios vascos. Acoger el concepto de España en el imaginario de la emancipación futura era, pues, y para Krutwig, defender a la misma burguesía ${ }^{22}$. En septiembre de 1966, Txillardegi, acusó a las tendencias obreristas de ETA de disfrazar el imperialismo bajo el manto del internacionalismo proletario: «propugnar así hoy el FRENTE DE CLASE [sic] frente a la burguesía, es hacer

20 Branka (abril de 1966). Nacionalismo revolucionario. (Número 1). Bélgica: exiliados nacionalistas vascos.

${ }^{21}$ Ibid.

22 Ibid. 
el juego a la burguesía y reforzar el imperialismo franco-español. Que este empeño se disfrace bajo una terminología marxista no cambia el carácter profundamente BURGUÉS Y REACCIONARIO [sic] de la empresa $»^{23}$.

Paralelamente a la reacción de Krutwig y de Txillardegi, el militante José Antonio Etxebarrieta, perteneciente junto con su hermano Txabi a esta corriente antiimperialista, escribió un informe titulado Análisis y crítica del españolismo social-chauvinis$t a$, en el que destacó que la obrerista Oficina Política planteaba «la lucha obrera en abstracto, prescindiendo de las condiciones concretas de Euskadi». Es decir, lo que se expresaba aquí era esencialmente que la asunción por parte de los miembros de la Oficina del proletariado como concepto subjetivo, como único nosotros en contradicción, destruía el marco de significado trabajado hasta entonces por la organización. Este marco habría diagnosticado una pluralidad de opresiones concretas que ahora querían encerrarse y superarse mediante un concepto el cual reseñaba tan solo a una parte de la totalidad negativa (Garmendia, 2000, p. 130; Casanova, 2008, p. 79; Equipo Hordago 5, 1979, pp. 127-128). De modo que la orientación obrerista se entendió como la renuncia a denunciar la polifonía concreta y particular de la negatividad en territorio vasco. En esta acusación se puede leer, por tanto, la disputa contra la defensa de un sujeto revolucionario homogéneo, ajeno a la determinación temporal y contextual concreta, y la apelación a la comprensión de la subjetividad de lo negativo desde una comunidad de luchas (Tischler, 2007, pp. 122-123) ${ }^{24}$.

Desde este punto, la Quinta Asamblea de ETA se programó como una respuesta ofensiva del sector antiimperialista, para el que no era posible abstraer la lucha contra la totalidad antagónica especificada sobre territorio vasco desde el mero prisma obrerista. Como se decía, su aportación fundamental no fue tanto continuar por esta senda defensiva (que se había iniciado, como vimos, con Krutwig o Txillardegi), sino esencialmente contraponer el esfuerzo de los miembros de la Oficina Política a través de la conceptuación alternativa de un sujeto que contuviera los fenómenos particulares de la represión identitaria intuida tiempo atrás. Es decir, se propuso la construcción conceptual de ese nosotros no-identitario que se formaba como constelación de los fragmentos dejados como ruina a partir del progreso doloso de la modernidad en los territorios vascos.

En el documento Ideología Oficial de ETA, redactado tras la expulsión de los miembros obreristas y la celebración de su segunda parte de la Quinta Asamblea en marzo de 1967, se impuso la doctrina del "nacionalismo revolucionario» como lucha contra el imperialismo y, a decir de la nueva ETA, como rechazo o «negación total de una realidad actual opresora» (Equipo Hordago 7, 1979, pp. 98-99). Dicho

${ }^{23}$ Branka (septiembre de 1966). Frente nacional o Frente de clase. (Número 2). Bélgica: exiliados nacionalistas vascos.

${ }^{24}$ Sobre el prioritario eje de la no-identidad frente a la clase en Adorno, ver: Buck-Morss, 1981, p. 180. 
rechazo a la negación de la negación efectuada por los poderes hispano-franceses solo podía realizarse a partir de un sujeto, el Pueblo Trabajador Vasco, que, como encarnación de los múltiples rechazos a la totalidad afirmada por la dictadura franquista, se elevaba en su misma contextualidad, indeterminación, inconsistencia y multiplicidad, como "constelación» en la cual se insertaba el tiempo mesiánico. Era una forma, consiguientemente, de contraponer los conceptos identificantes derivados de un tiempo homogéneo de progreso y la puerta de apertura hacia la posibilidad de realizar el excedente utópico del pasado, el denominado socialismo vasco. Un socialismo que pondría fin a la opresión nacional y social consecuencia de la modernidad capitalista ${ }^{25}$.

Asumiendo las clásicas categorías de "espacio de experiencia» y "horizonte de expectativa» formuladas por el iniciador de la escuela de la historia conceptual Reinhart Koselleck, podemos en paralelo entender este concepto como la puerta de apertura y articulación lingüística a las experiencias del pasado y del propio presente franquista como culminación del mismo. Precisamente, aunque de un modo quizás un tanto tosco, la unidad propuesta a través de las palabras "pueblo vasco» y "trabajador» remitía a las dos negatividades experimentadas con el triunfo de la modernidad sobre el País Vasco. Es decir, era no solo una categoría sincrónica - la remisión al presente experiencial franquista-, sino también diacrónica la experiencia del franquismo como culminación de la experiencia dolosa de la subjetivación moderna. Cuando ETA asumió este concepto inconsistente y tentativo lo hizo, por tanto, partiendo un marco conceptual previo, pero transformando a la vez y de forma práctica las dos categorías que habían expresado lo negativo sobre el territorio desde el siglo xIX (Cheirif Wolosky, 2014, pp. 85-100; Blanco Rivero, 2012, pp. 1-33; Koselleck, 2012, pp. 32-47; Cabrera, 2007, pp. 41-72). De otra parte, el concepto exhortaba, como condensador de la experiencia pretérita de opresión, a una expectativa de superación de la negatividad que lo constituía. Un punto de llegada futuro (el Estado independiente-socialista vasco) cuya indeterminación programática no permitía descubrir, en el mismo marco de significado pronóstico de ETA, si acabaría por reproducir el imperialismo conceptual contra el que se reveló o si asumiría una identidad consumada desde la misma conciencia de la no-identidad (Odriozola, 2016; Adorno, 2019, p.137).

\section{DOLOR, NEGATIVIDAD Y PRAXIS. LA ESTRATEGIA DE ETA}

Como es bien sabido, el marco de significado elaborado por ETA durante los aproximadamente 10 años que mediaron entre su fundación en 1959 y la conclusión de su Quinta Asamblea en 1967 dio como resultado la decisión de adoptar

${ }^{25}$ Zutik (enero de 1967). (Número 44). Boletín exterior de ETA. 
sin renuncia a una práctica que se orientó de forma principal por la violencia. El uso otorgado a esta última se determinó igualmente a partir de este proceso de creación y definitiva formación de aquel marco. La lectura adorniana hasta ahora realizada nos obliga, a tenor de la traslación de la teoría a una praxis muy concreta por parte del colectivo armado vasco, a continuar esta derivación desde las mismas coordenadas filosóficas trazadas por el filósofo de Frankfurt. Adorno fue, tal y como atestigua su filosofía y su propia actividad política, un intelectual reacio a derivar las conclusiones prácticas que se podían extraer de su propia filosofía. Su airado desprecio por participar en el movimiento del 68 en la Alemania Federal, en contraste con sus compañeros del gremio Herbert Marcuse, Michel Foucault o Jean-Paul Sartre (estos dos últimos en Francia), vino acompañado de una crítica concreta a aquel activismo que reclamaba su presencia. Como quedó reflejado en su obra tardía Marginalien zu Theorie und Praxis de 1969, para Adorno, la única praxis viable dentro de un mundo estructurado en torno a la falsedad era aquella que se atrincheraba en la reflexión intelectual. A partir de esta crítica, de esta actividad contemplativa que era, al tiempo, praxis teórica, se conseguiría destacar justamente aquella falsedad. El pensamiento, a decir de Adorno (2009b, p. 677), «es una actuación, la teoría es una figura de la praxis (...) es un modo de comportamiento real en medio de la realidad». En conclusión, la deriva que trasciende ese pensamiento, la praxis activista, se vuelve ineficaz en la transformación de la realidad, posibilitando al tiempo la realización de la totalidad y fetichizando la espontaneidad de los individuos (Adorno, 2009b, p. 682). La ineficacia en lograr el cambio se transformaría en violencia que solo participaría de este modo del mundo bárbaro que habría deseado cambiar. En resumen, según Silvia Schwarzböck, para Adorno, los «hombres, que desean emanciparse [mediante la praxis] crean las condiciones para que su emancipación fracase» (Schwarzböck, 2008, p. 155; véase también Buck-Morss, 1981, pp. 91-92). Dada la imposibilidad de que la totalidad de la razón instrumental no se efectivice, un grupo de autores interpretativos de Adorno, filósofos como por ejemplo Jürgen Habermas, Silvia Schwarzböck, Martin Jay, Herbert Schnädelbach o Albrecht Wellmer (Habermas,1992; Jay,1976; Schwarzböck, 2008; Wellmer, 1993), observarían en Adorno una irremediable descripción pesimista de la historia, en donde las salidas hacia la emancipación solo caerían en una reformulación continua, y sin concreción histórica, del dominio. Para otro grupo de autores, la obra de Adorno debe interpretarse, aun bajo la pérdida del eje clasista frente a la no-identidad, dentro de las coordenadas marxianas, y, en tal sentido, enmarcar su crítica dentro de la denuncia particular de la modernidad capitalista. Se sitúan aquí Gillian Rose, Fredric Jameson, o Susan Buck-Morss (Martín, 2017). Fuera del ámbito de la filosofía, en ámbito de la sociología y la politología, la escuela del marxismo abierto u Open Marxism (John Holloway a la cabeza) ha planteado, dentro de una perspectiva analítica similar a los anteriores intérpretes en su aproximación al pensamiento de Adorno, rescatar al filósofo de Frankfurt para contraponer el rechazo total a la 
dialéctica producido entre autores post-estructuralistas como Gilles Deleuze o los pertenecientes al post-operaismo (Paolo Virno, Antonio Negri, etc.). La perspectiva de esta escuela resulta sin duda provechosa para rescatar de manera flexible la esperanza en el pensamiento adorniano, al fundamentar la base de la articulación política de la emancipación no en la asunción la diferencia para rechazar la dialéctica, ni en la perspectiva de la realización sintética de la misma, sino en el grito. Es decir, en el dolor. En la contradicción producida entre la aspiración universal y el particular evidenciado a partir de dicho dolor. Es justamente en este punto en donde la filosofía de Adorno, en su pesimismo, y a partir de él, se vuelve esperanzadora. La praxis política es re-expuesta desde esta instancia de una nueva forma al sostenerse no desde un fin que se malogra, sino desde el fundamento constatativo de ese malograr. El cierre de la estructura política, en clara contraposición a los teóricos del proceso político, no como imposibilidad de articular la formación de un movimiento social, sino de constituirlo desde la preservación de su antagonismo al sistema establecido $^{26}$. Bajo nuestro punto de vista, el uso de la violencia de ETA a partir de mediados de los años 60 se orientó precisamente bajo ese presupuesto constatativo: la violencia, al menos tal y como ETA la planteó, no sustituía la teoría, no pretendía transformar ni realizar nada (la independencia y el socialismo), sino que, y en la medida en que iba encaminada a aumentar el dolor de las víctimas del sistema y no la de sus victimarios, abría la posibilidad de su acceso. El uso de la violencia daba cabida por tanto a constatar y pensar la no-identidad (Tischler, García Vela, 2017). En otro sentido, la violencia buscaría testificar el exceso/lo indecible conceptuado por ETA y constituido por el acto de enunciación performativo del franquismo, que subsumía - de manera violenta - a los trabajadores y a las minorías culturales del Estado bajo categorías abstractivas tales como «productores» o «españoles» (Escavy Zamora, 2009, p. 85; Lazzarato, 2020, p. 156; Butler, 2004; Austin, 1990; Allevi, 2015). En resumen: la concepción de un nosotros negado (llamado a partir de la Quinta Asamblea como PTV) había significado de forma unitaria, pero preservando su pluralidad, una realidad social que era opresiva de múltiples formas. Tales formas habían sido, a su vez, históricamente significadas de forma divergente y mutua-

${ }^{26}$ Una de las categorías propias de estos analistas de los movimientos sociales (entre los que podrían destacarse Peter Eisinger, Sidney Tarrow, Charles Brocket, Dieter Rucht o Donatella Della Porta) es la conocida como Estructura de Oportunidad Política (o EOP). Los cambios en esta estructura, en este contexto de acción política motivarían la constitución, la forma y el desarrollo de un movimiento social. Entre los cambios estructurales que motivarían la acción se encontraría la variable de los accesos sociales al poder. Los teóricos defensores de la EOP consideran que cuanto más abierto esté el acceso a la participación política más fácilmente puede constituirse la acción colectiva. A decir de Sidney Tarrow, «las personas racionales no atacan a menudo a oponentes bien pertrechados cuando las oportunidades están cerradas, pero un acceso parcial al poder les ofrece tales incentivos (...). El acceso a la participación es el primer incentivo importante para la acción colectiva» (Tarrow, 1997, p. 157; véase también McAdam, 1998, pp. 89-107). 
mente excluyente (la explotación capitalista frente a la uniformización etno-cultural o viceversa). La comprensión por ETA de que el conjunto de los habitantes en los territorios vascos sufría diversas formas de represión derivadas de un mismo acontecimiento histórico como era el franquismo, motivó la estrategia violenta descrita. Al tiempo, esta respuesta era estrictamente constatativa. El ciclo, como veremos a continuación, se cerraba cuando tras realizada la testificación, la organización buscó trasladar aquel marco de significado hacia la sociedad (indicando a la sociedad que formaba parte de una misma subjetividad pluralmente reprimida y planteando a la misma una salida para poner fin a aquella represión) (Cabrera, 2001, p. 57).

En los inicios de la organización, la comprensión por parte de ETA de que su lucha se enmarcaba dentro de la palingenesia de los rasgos culturales vascos, llevó a la organización a descartar la necesidad de articular una acción política que consistiera en «luchar contra un régimen dictatorial» o en aumentar «el descontento en las masas». Por su parte, la misión de ETA debía ser simplemente la de «edificar, educar a todo un pueblo para que recuerde que es vasco ${ }^{27}$. El periodo estival resultaría para ETA el periodo propicio para realizar actos para vivificar el sentimiento patriótico, realizando excursiones al monte, en donde se darían charlas sobre la historia vasca, se visitarían lugares significativos o se cantarían canciones patrióticas, y agrupándose en los grupos folclóricos tolerados por el régimen franquista (aunque, lógicamente, vaciados de su simbología nacionalista vasca) (De Guezala, 1991; De Pablo, 2010). Ya en 1959, ETA cometió algunos atentados de baja intensidad contra la sede del diario Alerta en Santander, la comisaría de policía de Indautxu (Bilbao) y el Gobierno Civil de Álava. Pese a que la actividad de ETA fue para las autoridades españolas indistinguible del de las otras expresiones de oposición nacionalistas vascas que se estaban produciendo en aquel momento, el consulado norteamericano de Bilbao captó la presencia de aquel nuevo colectivo, gracias a la obtención de uno de sus boletines (en concreto de un Zabaldu) (Mota Zurdo, 2021, pp. 15-16; Almeida Díez, 2019).

Más adelante, como indicó Aranzadi, la violencia comenzó en cierta manera a interpretarse como el elemento sustancial para la «producción simbólica generador de etnicidad» (Aranzadi, 1994, pp. 191). Aunque ya se ha explicitado anteriormente, no se comprende, tal y como haría el antropólogo vasco, a ese sujeto "étnico» como algo "a crear» a partir de la violencia de ETA $^{28}$. Como había remarcado

${ }^{27}$ Kemen (julio de 1959). iSeamos fieles al compromiso! (¿Número 1?). Boletín interno de ETA.

${ }^{28}$ Aranzadi (2001, p. 516) llegó a expresar al respecto de los usos dados a la violencia por parte de ETA, que: «la violencia (...) fue una reivindicación desesperada de existencia por parte de los residuos agonizantes de una comunidad nacionalista en aguda crisis de supervivencia que pugnaba por paliar su vacio y volverse tangible. No obstante, en la medida en que el espejo de la violencia dotó de una nueva imagen regenerada (...) produciendo con sus efectos una nueva y poderosa comunidad abertzale, la realidad así gestada pudo proyectarse hacia el 
Jaurégiberry, no fue ETA, sino el propio franquismo quien se encargó de producir esa no-identidad a partir de su mera existencia y la reproducción recurrente de su acto fundacional violento a través de las declaraciones de los Estados de Excepción $^{29}$. Estos eran proclamados tras la realización, por parte de ETA, de algún acto violento o como consecuencia del desarrollo de alguna movilización del movimiento obrero o nacionalista vasco (Jaurégiberry, 2007; Gurrutxaga, 1985, p. 297).

Bajo la influencia de Vasconia, en donde se apeló a construir una guerrilla de tipo anticolonialista, el documento de 1964 la Insurrección en Euskadi de la organización explicitó por primera vez este aspecto de provocación al régimen al indicar que «el militante revolucionario vasco ha de hacer la opresión más real y dura de lo que es (...) haciéndolo público». Para ETA, que aprobaría este documento en su Tercera Asamblea, era necesario realizar este movimiento, ya que el pueblo, de cara a lograr retornar instantáneamente a una condición de felicidad, disimulaba su dolor cotidiano gracias a la «prensa, radio, televisión, vino barato, fútbol espectáculo, conmemoraciones y fiestas nacionales». La cultura de masas, como vía que derivaba en una mayor cosificación de los individuos en la promesa de la felicidad

pasado». Si Aranzadi consideró que era la violencia de ETA la que generaba la étnica vasca (y no la misma represión del régimen), el historiador Luis Castells indicó que la presentación de los vascos dentro del imaginario nacionalista como un Nosotros doliente era la base de la teoría del conflicto histórico entre España y Euskadi esgrimida desde siempre por este movimiento social. Castells olvida, sin embargo, que en este imaginario (y en especial en la izquierda abertzale) no es importante la consideración de "víctimas de los vascos», sino la asunción de lo vasco en tanto que víctima. Tanto en la interpretación de Aranzadi como en la de Castells el imaginario nacionalista se escinde por tanto de la base contextual que posibilita ese texto que constitucionaliza lo vasco como víctima (como un reverso de la oficialidad establecida): la modernidad y su corolario concreto, la formación histórica (y, por supuesto, violenta) del Estado Español capitalista. De esta forma, por tanto, la violencia aparecería tan solo cuando ETA decidió ejercerla. De existir, el conflicto sería solo derivado de las armas de ETA y la renuncia a esta vía extremista de oposición, el fin toda violencia (Castells, 2018, pp. 43-73; Beck, Schlichte, 2014, pp. 28-35). Sobre esta temática particular, que es objeto de un encendido debate historiográfico, ver: Majuelo, 2020 y Rivera, 2020).

29 Tras la victoria franquista sobre las provincias vascas de Vizcaya y Guipúzcoa entre 1936 y 1937, fueron suprimidos sus Conciertos Económicos y declaradas «provincias traidoras». A partir de aquel momento, el Estado, a decir de Alfonso Pérez Agote (Pérez-Agote, 2008, p. 137), «impone una persecución absoluta de la cultura y los símbolos vascos, así como del nacionalismo y de toda forma de persecución social, según el código de guerra (traición), según una violencia fundacional, cuyos periódicos rituales de mantenimiento simbólico serán los estados de excepción. Estos tienen como misión objetiva fundamental la persecución indiscriminada sobre el territorio (.). La violencia indiscriminada del Estado actúa como agente integrador de todos aquellos que, no aceptando el Estado como legítimo, habitan ese territorio». 
instantánea, ya había sido denunciada por la organización cuatro años antes y a través de su Libro Blanco (Equipo Hordago 1, 1979, p. 97 del original) ${ }^{30}$.

Hasta la publicación de la Insurrección en Euskadi, los actos principales de ETA habían continuado las acciones que habían venido llevando a cabo los grupos de juventudes nacionalistas vascas durante los años precedentes: actos de sabotaje, violencia contra las cosas, pintadas y colocación de ikurriñas. A partir de aquel documento, la organización orientó sus acciones directas a la necesidad de aumentar las bases del dolor sistémico, como condición para la testificación/ constatación en la realidad social de la no-identidad (Fernández Soldevilla, Mota Zurdo, 2018; Odriozola, 2016, p.323; Casanova, 2008, pp. 20-32; Fernández Soldevilla, 2018, p. $89)^{31}$. A decir de Pedro Ibarra, en su clásica obra la Evolución estratégica de ETA, fue este documento en donde se pusieron las bases para la archiconocida estrategia de la acción-represión, que buscaba provocar al régimen para hacer visible la represión (Ibarra, 1989, p. 66; Fernández Soldevilla, 2016, p. 238). Pese a todo, durante el año 1964, ETA estuvo lejos de poder llevar a cabo tal estrategia, concentrándose en la realización de pintadas, lanzamiento de propaganda, el robo de armas y la agresión a un Guardia Civil en la localidad vizcaína de Sestao ${ }^{32}$.

En la Carta a los Intelectuales de finales de aquel año, ETA advirtió también de manera muy elocuente que la dictadura en su pretensión totalitaria hacia posible la evidencia de del dolor, de ese correctivo a la filosofía de la identidad que se expresaba sobre los cuerpos golpeados. En opinión del colectivo vasco, la visibilidad de ese cierre sistémico revelaba la falsedad del sistema mucho más claramente que bajo una democracia liberal: «podemos afirmar que la Dictadura del General Franco está siendo para nuestro pueblo infinitamente más positiva que una República democrático-burguesa, que hubiera ahogado nuestras aspiraciones sin crear unas tensiones como las que ahora disponemos para lanzar al pueblo a la lucha ${ }^{33}$.

30 ETA (1964). Insurrección en Euskadi:http://www.ehk.eus/es/iii-asamblea-cast/511documentos-iii-asamblea-cast/4261-la-insurreccion-en-euskadi-cast [Fecha de consulta: 14/09/2021].

31 AHPV. Archivo Histórico Provincial de Vizcaya. Bilbao, País Vasco. Gobierno Civil de Vizcaya/Caja 451/ Carpeta 22/ «Memoria Gobierno Civil de Bizkaia 1960».

32 AHPV. Archivo Histórico Provincial de Vizcaya. Bilbao, País Vasco. Gobierno Civil de Vizcaya/ Caja 452/ Carpeta 2/ «Expediente de la Dirección General de Seguridad-Jefatura Superior de Policía de Bilbao (16 de enero de 1965)».

${ }^{33}$ ETA (1965). Carta a los intelectuales. Recuperado el 16 de mayo del 2021 de http://www. ehk.eus/es/iv-asamblea-cast/514-documentos-iv-asamblea-cast/4264-carta-a-los-intelectuales1965-cast. ¿No guarda esta declaración una sintonía con la filosofía de Adorno? En su Dialéctica Negativa expresó lo siguiente: «Es precisamente el insaciable principio de identidad el que perpetúa el antagonismo mediante la represión de lo contradictorio. Lo que no tolera nada que no sea como él mismo impide la reconciliación por la cual se toma. La violencia de la igualación reproduce la contradicción que extirpa» (Adorno, 2005, p. 139. 
La estrategia de la acción violenta como corolario para constatar la existencia de un nosotros negado en la realidad social, vino a completarse a partir de la aprobación del ya citado documento de las Bases Teóricas de la Guerra Revolucionaria en la Cuarta Asamblea de junio de 1965. En este nuevo papel teórico explícitamente se indicó:

La misión de las fuerzas de represión del Estado español sería impedir con su lucha que el pueblo vasco sea reconocido como nación...pero la lógica de la lucha les obliga a hacer ellos mismos este reconocimiento en la práctica del combate. En el momento en que la represión se hace lógica con sus propios fines, da al pueblo oprimido su naturaleza como Nación. Si los vascos somos capaces de desarrollar un proceso de acción-represión, habremos provocado una reacción en los Estados opresores y en los medios internacionales... (Equipo Hordago 3, 1979, p. 514).

Es decir, para ETA resultaba claro que la provocación al régimen de Franco permitiría obtener el estatus de reconocibilidad a la nación vasca que aquel mismo régimen buscaba negar a toda costa. El uso de la violencia se encaminó, por tanto, y como se indicaba, no en la pretensión de realizar la independencia y el socialismo como objetivos últimos del ideario de ETA, sino de constatar y hacer visible una identidad vasca constituida, como visibilizaba la propia represión, como no-identidad. Dado que ETA buscaba trasladar o extremar el dolor sistémico hacia la población para constatar su propia interpretación de la identidad vasca como no-identidad, podríamos denominar a este período estratégico como el momento del martirio, y en atención a la misma etimología de esta palabra (del griego: $\mu \alpha \rho \tau u \rho ı v), ~ q u e$ significa dar testimonio.

La Cuarta Asamblea elevó además una línea de actuación divergente al mero uso de la violencia para provocar al régimen. Ya en la Insurrección en Euskadi se propuso, por primera vez, la creación de una estructura destinada a crear unas «jerarquías paralelas», a partir de las cuales, y habiendo realizado la acción violenta de provocación, «el pueblo ya no obedecerá más al invasor sino a nosotros» ${ }^{34}$. En las Bases Teóricas de la Guerra Revolucionaria se había indicado justamente que, ante la represión descargada por las autoridades de la dictadura, era necesario que el pueblo antepusiera la «rebeldía» al "pánico» (Equipo Hordago 3, 1979, p. 515). Desde la Tercer Asamblea, ETA había aprobado una línea de actuación que destacaba la necesidad del contacto de la organización con esa sociedad civil oprimida. A principios de los años 60, ETA había participado ya en conflictos laborales, como en la conocida como «Huelga de los 10 minutos» en el entorno fabril de la ría de

${ }^{34}$ ETA (1964). Insurrección en Euskadi. Recuperado el 16 de mayo del 2021 de http:// www.ehk.eus/es/iii-asamblea-cast/511-documentos-iii-asamblea-cast/4261-la-insurreccion-eneuskadi-cast [Fecha de consulta: 14/09/2021]. 
Bilbao, que llevó a la detención de 27 militantes de las células obreras de ETA. De hecho, la propia Jefatura Superior de Policía de Bilbao destacó en su memoria del año 1963 que ETA tenía una cierta influencia en industrias como Aguirena y Laurak, y que era el único punto destacable de conflictividad laboral durante aquella anualidad (Abasolo, Mendaza, Bustillo, 2014, p. 492) ${ }^{35}$. En la Cuarta Asamblea, la organización dividió la sección que se encargaría de la violencia de otras tres secciones destinadas a proyectar socialmente el marco de alternativa de ETA: al bloque o frente militar se le añadieron la Organización Paralela, la Oficina Política y la activista. A partir de este momento, la estrategia de la acción-represión quedó aprobada, así como las secciones destinadas expresamente a la movilización social (Ortzi, 1975, p. 390; Sullivan, 1988, p. 58; Fernández Soldevilla, 2016, p. 239) ${ }^{36}$.

Como veíamos, desde su nacimiento ETA había forjado su actividad política desde dos planos. En un primer momento el objetivo era formar a la población en la cultura e historia vascas. En el segundo momento, se trataba de constatar una no-identidad. En ambos casos, aquella estrategia se derivaba claramente del marco de significado elaborado por ETA. Si en un primer período se buscó recuperar la esencia vasca perdida, la segunda etapa se orientó a destacar la relación dialéctica/ de contradicción que el conjunto de los habitantes de los territorios vascos mantenía con respecto a la modernidad capitalista expresada a través de la dictadura de Franco. A partir de la Cuarta Asamblea, ETA buscaría no solo constatar la lo vasco como no-identidad dentro del franquismo, sino, y a partir de del logro de ese primer objetivo mediante el uso de la violencia, trasladar su marco de alternativa hacia aquella sociedad. Es decir, para ETA no bastaba con hacer visible el dolor de la represión como herramienta para mostrar públicamente la falsedad del sistema. Para el colectivo había que hacer ver a la población que formaba parte de una misma subjetividad negada y proyectar la fórmula, el marco de significado pronóstico, que realizaría el fin del dolor que constituía aquella misma subjetividad: el logro de la independencia de los territorios vascos y la consecuente formación de una sociedad igualitaria. Durante este período, la actividad de concienciación adquirió tal importancia en ETA que llegó a eclipsar a unas ramas militares aún no lo suficientemente estructuradas. De facto, la única actividad de ETA entre 1965 y 1966 se sitúo en el terreno obrero, siendo participe de la organización del incipiente sindicalismo de oposición de las Comisiones Obreras. ETA participó, por ejemplo, en la creación de

35 AHPV. Archivo Histórico Provincial de Vizcaya. Bilbao, País Vasco. Gobierno Civil de Vizcaya/ Caja 453/Carpeta 1/«Expediente de la Dirección General de Seguridad-Jefatura Superior de Policía de Bilbao (16 de enero de 1964)».

${ }^{36}$ El fin de esta estrategia de la acción-represión en la organización ETA es objeto de debate. Autores como Pedro Ibarra proponen el año 1974 (año en el que aparece el primer partido de la izquierda abertzale, LAIA, y se forman ETA-Político Militar y ETA-Militar). Francisco Letamendia indicó que la fecha más oportuna era 1977, mientras que Florencio Domínguez retrasó esta hasta el año 1978. Ver Sánchez-Cuenca, 2001, p. 65. 
la Comisión Obrera Provincial de Guipúzcoa. Lógicamente, este hecho, protagonizado por la recién creada Oficina Política, invalidó la estrategia general y fue un importante factor para la escisión de las corrientes obreristas en el interior del grupo (Odriozola, 2016, p. 310; Garmendia, 1979, p. 185; Jaúregui, 1981, pp. 282-283).

En la Quinta Asamblea, en donde, como decíamos, se dio a conocer por primera vez el concepto de Pueblo Trabajador Vasco y se expulsó a las corrientes obreristas, se obtuvo una expresión más acabada de este entramado estratégico general. En aquella asamblea la organización se dividió en cuatro frentes estratégicos, siguiendo los preceptos antiimperialistas que había estimulado Krutwig en sus escritos, especialmente en su artículo La Cuestión Guerrillera de 1966; «la guerrilla reducida meramente al frente militar es un destacamento armado que fácilmente será destruido por los enemigos ${ }^{37}$. Se pusieron así en pie los frentes político, socioeconómico y cultural (además del propio frente militar) que estarían comandados por un líder provincial (herrialdeburu) dependiente a su vez del Comité Ejecutivo Táctico de la organización (Equipo Hordago 7, 1979, p. 95; Fernández Soldevilla, 2016, p. 243; Letamendia, 1994, p. 312). Aunque, de hecho, y como se expresó en la Ideología Oficial de la organización, todos los frentes quedaron subordinados a la estrategia de la acción-represión, el frente militar, es decir, aquel destinado a hacer uso de la violencia, siguió siendo la sección que constataría la subjetividad conceptuada; el PTV. Mientras, el resto de frentes se impuso como tarea la traslación del marco de alternativa de ETA. Los Frentes político, socioeconómico y cultural tratarían así de trasladar públicamente la significación concreta dada por ETA a una realidad social que se expresaba como angustia y dolor sobre los cuerpos, posibilitando, así, un nuevo vínculo relacional y de experiencia entre los individuos sometidos al mismo padecimiento y ante el poder político y económico establecido. Si la violencia era pues la apertura al pensamiento, los frentes no armados situaban la reflexión concreta sobre la experiencia opresiva vivida (Verano, 2019; Le Breton, 1999, p. 440; Equipo Hordago 7, 1979, p. 99). Encontramos una forma más clara de este razonamiento a través de la publicación del Zutik 51, de marzo de 1969; un año después de los acontecimientos de 1968, que más tarde usaremos de ejemplo de la nueva estrategia. En este número, la organización ETA devenida de la Quinta Asamblea expuso de forma nítida que «para realizar la Revolución Socialista Vasca no basta con que el PTV exista y que un sistema que no está hecho para responder a sus necesidades lo oprima, es preciso además que los oprimidos tomen conciencia». Para ETA pues era necesario clarificar "ante el pueblo su condición de oprimido» mediante los frentes (especialmente a través de los no armados) ${ }^{38}$. Por consiguiente, para el colectivo no bastaba una estrategia encaminada a lograr el martirio colectivo. Hacía

37 Branka (septiembre de 1966). Estrategia guerrillera (Número 2). Bélgica: exiliados nacionalistas vascos.

${ }^{38}$ Zutik (marzo de 1969). (Número 51). Boletín exterior de ETA. 
falta disponer al pueblo a superar el dolor aún a riesgo de padecerlo más intensamente. En esta línea interpretativa, autores como Guilles Deleuze, Michel Fouacault, Slavoj Žižek, Silvia Schwarzböck o - desde el punto de vista específico del terrorismo- Srećko Horvat (Deleuze, 1961/2001; Foucault, 1998; Žižek, 2004, pp. 69-70; Horvat, 2018, pp. 75-81), han destacado precisamente el acto político que constituye el deseo de sentir deliberadamente un padecimiento o un dolor. Una actividad que es propiamente masoquista y que fue, sin embargo, en su descripción como proceso de adaptación a la realidad afirmada, como posible expresión del deseo de identificación con el poder y el ataque a los débiles, expresamente criticada por Adorno (y Horkheimer) (Horkheimer, Adorno, 1998, p. 198; Adorno, 2009; Adorno, 2001, p. 63). Rompiendo aquí con esa interpretación y siguiendo en este punto a Deleuze, que desliga la figura del masoquismo del sádico, puede decirse, en palabras del propio autor francés que:

el masoquista, que considera la ley como un proceso punitivo empieza por hacerse aplicar la punición; y en esta punición padecida encuentra, paradójicamente, una razón que lo autoriza y que incluso le ordena experimentar el placer que la ley estaba supuestamente encargada de prohibirle (...). El sufrimiento no es la causa del placer sino la condición previa indispensable para su advenimiento. (Deleuze, 2001, p. 92-93).

Los Frentes no armados de ETA expresaron justamente, y bajo nuestra lectura, esa necesidad de obtener un placer mediante el dolor. No era ya solamente testificar, constatar la no-identidad, sino de afirmar de manera consecuente aquello que el sistema se habría afanado en negar. Desde este plano, el PTV, concienciado por ETA, ya no resultaría solamente víctima constatada de la dictadura, sino, y en la disposición de vivir en los rasgos negados bajo la amenaza asumida de la muerte, resistente a ese régimen. No era pues una mera adaptación, sino el goce racional de un suplicio que imposibilitaría la reproducción victimológica de las propias víctimas. Esta secuencia, esta traslación de la condición del martirio a la figura del masoquista es fácilmente observable en el militante de ETA, y claro protagonista de la Quinta Asamblea, Txabi Etxebarrieta (Casquete, 2018; Frankl, 2009, p. 128).

Etxebarrieta fue, como es bien conocido, el primer militante de ETA que dio muerte a un Guardia Civil, José Antonio Pardines, y también el primer miembro de la organización en fallecer, cuando fue tiroteado por la propia Guardia Civil. Aquella acción, producida el 7 de junio de 1968, no había sido premeditada, pero, a partir de ella, se logró cambiar la historia del País Vasco y España (Fernández Soldevilla, 2018, p.78). El historiador Ludger Mees, valiéndose del poema de Joxe Azurmendi Manifestu atzeratua, indicó que con los asesinatos de Pardines y Etxebarrieta «los vascos comenzaron a tener aparentemente historia. Emergieron del túnel negro de la insignificancia histórica, apareciendo en los medios internacionales y captando el interés de los académicos...» (Mees, 2019, p. 2). 
A pesar de que aquella acción violenta no había sido premeditada, ETA había decidido poco antes que había que, en palabras de Mario Onaindia, «romper con los fantasmas» y lanzarse decididamente a la acción política. La organización resolvió así que debía atentar contra el odiado jefe de la Brigada Político Social de Guipúzcoa y afamado torturador, Melitón Manzanas, y su homólogo vizcaíno, José María Junquera. La tarea para asesinar a Manzanas había recaído en Etxebarrieta, que provocó aquella secuencia referida cuando se disponía a preparar el atentado e iniciar la espiral de la acción-represión. Etxebarrieta, que era un activo intelectual importante de la organización, había manifestado desde hacía tiempo su predisposición a la muerte. La Patria Vasca, según se expresaba en su poemario, debía nacer como vida de su misma sangre (Etxebarrieta, 1996, p. 91). Como decíamos, para los nacionalistas vascos derrotados en 1937, el franquismo se significó como el calvario, la pasión que acontecía a la resurrección de la misma Patria Vasca. Su acto de resistencia, propiamente martirológico, se basó en aceptar los golpes, el encarcelamiento o en la espera de los aliados occidentales para tratar de liberar a Euskadi del franquismo. Etxebarrieta buscó matar primero para, y en la reacción buscada de las autoridades policiales a su acto, lograr testimoniar así un cuerpo perseguido. En él no había un mero martirio como padecer pasivo. Su deseo de ser matado tras haber matado él evidenciaba la disposición a la muerte. A partir de este deseo, propiamente masoquista, se obtendría la confirmación del dolor previamente infringido y la evidencia de que el poder no podría seguir ejerciendo la represión. Dicho de otra manera, si por lo negado por la dictadura de Franco se estaba dispuesto a morir, ninguna represión podría seguir aplicando el correctivo de la identidad. Fue este proceso, como decíamos, el que, bajo nuestra lectura ETA trató de trasladar a la población; esta no debía meramente evidenciar su condición de víctima, de mártir, si no que debía desear esta condición como precio a pagar por vivir libremente. La propia muerte de Etxebarrieta serviría, a decir de Jesús Casquete, como mecanismo de integración comunitaria a la causa de ETA, como ejemplo para futuros militantes (y a la propia población) y como modelo de sublime y desinteresada abnegación al objetivo de la liberación (Zulaika, 2007, p. 21; Garmendia, 2000, p. 141; Casquete, 2017, pp. 99-100).

\section{CONCLUSIÓN}

Desde su nacimiento y hasta 1967, ETA vivió una larga trayectoria en la que tuvo lugar la creación de un marco de significado muy concreto. En el centro de la evolución de este imaginario se encontró la discusión en torno a la subjetividad. En los inicios, ETA, imbuida por unas lógicas palingenésicas, se decidió por recuperar la cultura vasca en la esperanza de hacer recordar al pueblo su condición de vasco. Bajo este principio, que buscaba retornar a una supuesta autenticidad, ETA se vio, 
pese a la retórica socialcristiana, influida por una doctrina de cierto carácter xenofóbico. Estratégicamente, y como consecuencia de este imaginario, la tarea de la organización pasó por organizar grupos de estudio o de montaña e influir en las distintas asociaciones culturales vascas toleradas por el régimen. Tempranamente, la cada vez mayor conflictividad laboral en el seno de las fábricas llevó a ETA a acercarse con más arrojo a la problemática obrera, iniciándose una recomposición de los marcos xenofóbicos de primera hora, que quedaron descartados. A este primer paso dado a principios de los años 60 le acompañó una obra que dotó de una novedosa estructuración al nacionalismo vaso defendido por ETA. En efecto, en 1963, el libro Vasconia, redactado por el intelectual vasco-germano Federico Krutwig, comenzó a pensar la identidad vasca como el negativo de la sociedad afirmada devenida del triunfo de la modernidad. A partir de la irrupción de esta última en los territorios vascos se habría constituido en ellos una subjetividad cosificada, amoldada a la identidad ideal del concepto. Al tiempo, se habría destruido la posibilidad de inferir una sociedad socialista desde el mismo desarrollo de la historia vasca, cercenada en el transcurrir del progreso. Con Krutwig se puso el acento en el dolor en la constitución de la nueva identidad vasca, a la que se habrían incorporado, como agentes explotados bajo la modernidad capitalista, los trabajadores inmigrantes. El nuevo nosotros vasco sería, por consiguiente, una totalidad antagónica; un nosotros formado de todo aquello que, en los territorios vascos, no cabía en el sistema franquista establecido. Desde esta influencia y sus contactos en el seno del movimiento obrero, ETA incorporó, fundamentalmente a partir de 1963, a los asalariados inmigrantes a la comunidad del dolor, rehaciendo de forma clara su marco de significado inicial y reformando su estrategia en relación a la violencia. A partir de este período, el uso de una estrategia de corte armado se orientaría progresivamente no en realizar el proyecto de la independencia vasca con respecto a España y Francia, sino en constatar la presencia de esa comunidad del dolor; de esa noidentidad significada por la propia organización. Aquel nuevo nosotros, el Pueblo Trabajador Vasco, se conceptuó oficialmente por ETA al amparo de la celebración de su Quinta Asamblea. En aquella asamblea, celebrada entre los años 1966 y 1967, se realizó, de forma paralela, una composición acabada de la nueva estrategia en relación al renovado marco de significado. Tiempo atrás, el colectivo había desarrollado ya una tentativa estructuración sectorial, dividiendo las funciones armadas, aún por entonces escasas, con otras tareas de concienciación y encuadramiento político de la ciudadanía. En la Quinta Asamblea, el Frente Militar, aquel que haría uso de la violencia, se encargaría de dar testimonio de la totalidad antagónica habitante en el territorio vasco. La violencia, como se había explicitado en anteriores documentos de la organización, tendría en adelante, por función, la provocación al régimen franquista. Con la respuesta de la dictadura a la acción previa de ETA, el grupo armado debía lograr que hacer visible la represión indiscriminada contra los habitantes de los territorios vascos, testimoniando la presencia territorial de 
un nosotros constituido justamente de la represión y adaptación cotidiana a una identidad ideal impuesta.

El marco de significado de la organización no se limitó simplemente en concebir a ese nosotros subjetivo antagónico (el Pueblo Trabajador Vasco) y a constatarlo en la realidad social, sino que proyectó al unísono un horizonte para su liberación: la independencia de los territorios vascos y la consecución del socialismo. Los Frentes no armados de ETA debían trasladar precisamente esa alternativa a la población y tras haber experimentado esta el correctivo de la identidad, expresado a través de la represión policial. En resumen, ETA quiso hacer visible el dolor y ofrecer al PTV, como concepto subjetivo formulado por ETA, una alternativa para superarlo. En el cambio de un momento estratégico a otro, y como ejemplificaba el militante de ETA, Txabi Etxebarrieta, se producía una transición entre el momento de martirio (la constatación del nosotros negado) al momento del masoquismo (el deseo del dolor como paso para superar el correctivo de la negación).

\section{REFERENCIAS BIBLIOGRÁFICAS}

Abasolo, P. Mendaza, D., Bustillo, J. (2014). Nuestro mayo rojo. Aproximaciones a la historia del movimiento obrero vasco (1789-1990). Tafalla: Txalaparta.

Adorno, T., Horkheimer, M. (2016). Dialéctica de la llustración. Madrid: Akal.

Adorno, T. (2005). Dialéctica Negativa. La Jerga de la Autenticidad. Madrid: Akal.

Adorno. T. (2009). Disonancias / Introducción a la sociología de la música. Madrid: Akal.

Adorno, T. (2001). Minima moralia. Madrid: Taurus.

Adorno, T. (2017). Ontología y dialéctica lecciones sobre la filosofía de Heidegger (L. S. Carugati, Trad.). Buenos Aires, Argentina: Eterna Cadencia.

Adorno, T. (2019). Sobre la teoría de la historia y de la libertad. Argentina: Eterna Cadencia.

Adorno, T. (2009b). Notas marginales sobre teoría y praxis. En T. Adorno, Critica de la cultura y sociedad II. Madrid: Akal. 
Agirre Odriozola, J. (2017). Hitza hitz. Txillardegirekin solasean. Donostia-Baiona: Elkar.

Allevi, J.A. (2015). Subjetividades, lo político y la política: derivas de una discusión teórica. Athenea Digital, 15, pp. 149-172. https://doi.org/10.5565/rev/ athenea.1509

Aranzadi, J. (2001). El escudo de Arquíloco. Sobre mesías, mártires y terroristas. Madrid: Antonio Machado.

Aranzadi, J. (1981). Milenarismo Vasco. Edad de oro, etnia y nativismo. Madrid, MD: Taurus.

Aranzadi, J. (1994). Violencia etarra y etnicidad. Ayer, 13, pp. 189-208.

Almeida Díez, A. (2020). La Hipótesis Revolucionaria. Nacionalismo Vasco y la Crítica a la Modernidad. Araucaria. Revista Iberoamericana de Filosofía, Política, Humanidades y Relaciones Internacionales, 43, pp. 119-142. https://doi. org/10.12795/araucaria.2020.i43.06

Almeida Díez, A. (2019). Resistencias. La oposición interior del nacionalismo vasco a la dictadura de Franco (1937-1959). El Futuro del Pasado, 10, pp. 569-606. https://doi.org/10.14516/fdp.2019.010.001.022

Austin, J. L. (1990). Cómo hacer cosas con palabras. Palabras y acciones. Barcelona: Paidos.

Barandiaran, M. (s. f.). Publicaciones periódicas del PNV (1939-1975). Bilbao, PV: Sabino Arana Fundazioa.

Bastida Freixedo, X. (1997). La búsqueda del grial. La teoría de la nación en Ortega. Revista de Estudios Políticos, 96, pp. 43-76.

Beck, C. J., Schoon, E. W. (2019). Terrorism and Social Movements. En D. A. Snow et al. (eds.), The Wiley Blackwell Companion to Social Movements (pp. 698-713). Oxford: Wiley. https://doi.org/10.1002/9781119168577.ch40

Beck, T. K., Schlichte, K. (2014). Theorien der Gewalt zur Einführung. Hamburg: Junius.

Benjamin, W. (2004). Libro de los Pasajes. Madrid, MD: Akal. 
Blanco Rivero, J. J. (2012). La historia de los conceptos de Reinhart Koselleck: conceptos fundamentales, Sattelzeit, temporalidad e histórica. Politeia, 49, pp. 1-33.

Bonefeld, W. (2007). Praxis y constitucionalidad: Notas sobre Adorno. En J. Holloway, F. Matamoros, S. Tischler (comps.), Negatividad y revolución, Theodor Adorno y la política (pp. 129-156). Buenos Aires: Herramienta.

Box Z. (2013). El nacionalismo durante el franquismo. En A. Morales Moya, J. P. Fusi, y A. De Blas Guerrero (dirs.), Historia de la nación y del nacionalismo español (pp. 903-920). Barcelona: Galaxia Gutenberg.

Brull Gregori, R. (2007). La Dialéctica Negativa en Adorno: la aplicación a la teoría social. (Tesis inédita de doctorado). Universitat de Valencia, Valencia.

Buces, J. (2018). La represión franquista durante el Estado de Excepción. En J. Buces, J. Egaña, F. Etxeberria, J. Mirena Landa, L. Pego, R. Perez, Gipuzkoa en Estado de Excepción (pp. 30-174). Leitzaran: Aranzadi/UPV-EHU.

Buck-Morss, S. (1981). Origen de la dialéctica negativa. Theodor W. Adorno, Walter Benjamin y el Instituto de Frankfurt. Madrid, México D. F. Bogotá: SigloXXI.

Bullain, I. (2011). Revolucionarismo patriótico. El Movimiento de Liberación Nacional Vasco (MLNV). Orígenes, ideología, estrategia y organización. Madrid: Tecnos.

Butler, J. (2004). Lenguaje, poder e identidad. Madrid: Síntesis.

Cabrera, M. Á. (2001). Historia, lenguaje y teoría de la sociedad. Madrid: Cátedra.

Cabrera, M. Á. (2007). La historia postsocial: Más allá del imaginario moderno. En T. M. Ortega López (ed.), Por una historia global. El debate historiográfico en los últimos tiempos (pp. 41-72). Granada, AN: Universidad de Granada-Prensas Universitarias de Zaragoza.

Cabot, M. (2007). El pensamiento de Th. W. Adorno: balance y perspectivas. Palma: Universitat de les Illes Ballears.

Cabot, M. (1999). La idea adorniana de domino de la naturaleza y su repercusión en la estética. Taula. Cuaderns de pensament, 31/32, pp. 33-48.

Casanova, I. (2008). ETA, 1958-2008: medio siglo de historia. Tafalla, PV: Txalaparta. 
Casquete, J. (2009). En el nombre de Euskal Herria. La religión política del nacionalismo vasco radical. Madrid: Tecnos.

Casquete J. (2017), Epic, memory and the making of an uncivil community. En R. Leoniso, F. Molina, D. Muro (eds.), ETA's Terrorist Campaign. From violence to politics, 1968-2015 (pp. 87-102). Oxon: Routledge. https://doi. org/10.4324/9781315657806-6

Casquete, J. (2018). Txabi Echebarrieta: Kondaraizko martiri bat edo martiri baten kondaira. En G. Fernández Soldevilla, I. Dominguez Iribarren (coords.), Pardines. ETA erailtzen hasi zenean (pp. 169-196). Madrid: Tecnos-Gipuzkoako Foru Aldundia.

Castells, L. (2018). La triada salvífica: sufrimiento común, reconciliación social, teoría del conflicto. En A. Rivera (ed.), Naturaleza muerta. Usos del pasado en Euskadi después del terrorismo (pp. 43-73). Zaragoza: Prensas Universitarias de Zaragoza.

Cheirif Wolosky, A. (2014). La teoría y metodología de la historia conceptual en Reinhart Koselleck. Historiografías, 7, pp. 85-100.

De Guezala, L. (1991), Resistencia cultural durante el franquismo. El grupo de danzas Dindirri. Bilbao: SAF.

De la Granja, J. L. (1984) La izquierda nacionalista vasca en la II República: ANV. IPES-Cuadernos de Formación («nacionalismo y socialismo en Euskadi»), 4, pp. 123-134.

Deleuze, G. (2001). Presentación de Sacher-Masoch. Lo frío y lo cruel (I. Agoff, Trad.). Buenos Aires: Amorrortu.

De Pablo, S. (2010). Lengua e identidad nacional en el País Vasco: Del franquismo a la democracia. En C. Legarde (ed.), Le discours sur les langues d'Espagne. El discurso sobre las lenguas españolas, 1978-2008 (pp. 53-64). Perpignan: Presses Universitaires de Perpignan. https://doi.org/10.4000/books.pupvd.303

De Pablo, S., Mees, L., Rodríguez Ranz, J. A. (2001). El Péndulo Patriótico. Historia del Partido Nacionalista Vasco II: 1936-1979. Barcelona: Crítica.

Domínguez Iribarren, F. (1998). ETA: estrategia organizativa y actuaciones (19781992). Bilbao: Universidad del País Vasco, Servicio Editorial. 
Dussel, E. (1994). 1492. El encubrimiento del otro. Hacia el origen del mito de la modernidad. La Paz: Plural-UMSA.

Elorza, A. (1978). Ideologías del nacionalismo vasco. Donostia: Haranburu.

Equipo Hordago 1/2/3/6/7 (1979). Documentos Y. San Sebastián: Hordago.

Escuela Cruz, C. M. (2017). Prioridad materialista del objeto. Sobre la mediación sujeto- objeto en la obra de Theodor W. Adorno. Daimon. Revista Internacional de Filosofía, 70, pp. 181-196. https://doi.org/10.6018/daimon/230751

Escavy Zamora, R. (2009). Pragmática y textualidad. Murcia: Universidad de Murcia.

Etxebarrieta, T. (1996). (Ed. Lorenzo Espinosa, J. M.). Poesía y otros escritos. Tafalla: Txalaparta.

Faye, E. (2018). Heidegger. La introducción del nazismo en la filosofía. Madrid: Akal.

Frankl, V. (2009). El hombre doliente "fundamentos antropológicos de la psicoterapia» (Diorki, Trad.). Madrid: Herder.

Fernández Guerrero, O. (2019). El dolor como encuentro con la alteridad. Isegoría. Revista de Filosofía, Moral y Política, 60, pp. 169-188. https://doi.org/10.3989/ isegoria.2019.060.10

Fernández Soldevilla G. (2017). De Aberri a ETA, pasando por Venezuela. Rupturas y continuidades en el nacionalismo vasco radical (1921-1977). Bulletin d'Histoire Contemporaine de l'Espagne, 51, pp. 219-264. https://doi.org/10.4000/ bhce.751

Fernández Soldevilla, G. (2019). El camino al infierno. ETA, desde sus orígenes a los años de plomo (1958-1981). En Avilés J., Azcona J. M., Re, M., (Ed.), Después del 68: La deriva terrorista en Occidente (pp. 303-332). Madrid: Sílex.

Fernández Soldevilla, G. (2016). La voluntad del Gudari. Génesis y metástasis de la violencia de ETA. Madrid: Tecnos.

Fernández Soldevilla G., López Romo, R. (2010). ¿Enemigos internos o nuevos aliados? Los inmigrantes y el nacionalismo vasco radical (1959-1979). Alcores, 10, pp. 193-217. 
Fernández, G., López Romo, R. (2018). From ethnic exclusion to terrorism? The case of Basque nationalism. Journal of Iberian and Latin American Studies, 24, pp. 443-459. https://doi.org/10.1080/14701847.2018.1531218

Fernández Soldevilla, G., Mota Zurdo, D. (2018). El americano impasible. El Correo. Recuperado el 27 de abril de 2020, de http://www.academia. edu/37470359/ El_americano_impasible.pdf.

Fernández Soldevilla, G. (2018). Odol Hotzean: José Antonio pardinesen hilketa (eta honen aurrekariak). En Fernández Soldevilla, G., Domínguez Iribarren, F. (Koord.), Pardines. ETA erailtzen hasi zenean (pp. 77-113) Madrid: Tecnos.

Foucault, M. (1998). Historia de la Sexualidad. Madrid: Siglo XXI.

Garmendia, J. M. (1979). Historia de ETA. 1979 (Vol. 1). Bilbao: Haramburu.

Garmendia, J. M., González Portilla, M. (1993). Crecimiento económico y actitudes políticas de la burguesía vasca, en la postguerra. En M. Ortiz Heras, D. Ruiz González, I. Sánchez Sánchez (coords.), España franquista: causa general y actitudes sociales ante la dictadura (pp. 179-195). Albacete: Universidad de Castilla-La Mancha.

Garmendia, J. M. (2000). ETA: nacimiento, desarrollo y crisis (1959-1978). En A. Elorza (coord.), La historia de ETA (pp. 77-168). Barcelona: Temas de Hoy.

González Calleja, E. (2016). Los estudios sobre terrorismo: balance de los últimos 25 años. Espacio Abierto. Cuaderno Venezolano de Sociología, 4, pp. 61-76.

Gunning, J. (2009). Social movement theory and the study of terrorism. En R. Jackson, M. Breen Smyth, R. Jackson (eds.), Critical Terrorism Studies. A new research agenda (pp. 156-177). Oxon: Routledge.

Gurrutxaga, A. (1985). El código nacionalista vasco. Barcelona: Anthropos.

Gurrutxaga, A. (2002). La mirada difusa: dilemas del nacionalismo. Irún: Alberdania, 2002.

Habermas, J. (1992). El discurso filosófico de la modernidad. Madrid: Katz.

Horkheimer, M., Adorno, T. (1998). Dialéctica de la llustración. Madrid: Trotta. 
Horvat, S. (2018). El discurso del terrorismo. Iruñea-Pamplona: Katakrak.

Horkheimer, M. (2010). Crítica de la razón instrumental. Madrid: Trotta.

Ibarra, P. (1989). La evolución estratégica de ETA. Donostia: Kriselu.

Jackson, R. (ed.). (2016). Routledge Handbook of Critical Terrorism Studies. LondonNew York: Routledge. https://doi.org/10.4324/9781315813462

Jay, M. (1976). The Dialectical Imagination. A History of the Frankfurt School and the Institue of Social Research 1923-1950. London: Heinemann.

Jauregui, G. (1981). Ideología y estrategia política de ETA. Madrid: Siglo XXI.

Jauréguiberry, F. (1983). Question nationale et mouvements sociaux en Pays Basque. Paris: Sociologie. Ecole des Hautes Etudes en Sciences Sociales (EHESS).

Jaurégiberry, F. (2007). Question nationale et mouvements sociaux en Pays Basque. Paris: I'Harmattan.

Jiménez Martínez, M. A. (2015). El corpus ideológico del franquismo: principios originarios y elementos de renovación. Estudios Internacionales, 180, pp. 1145. https://doi.org/10.5354/0719-3769.2015.36430

Joas, H., Knöbl, W. (2016). Teoría social. Veinte lecciones introductorias. Madrid: Akal.

Koselleck, R. (1993). Futuro pasado. Para una semántica de los tiempos históricos. Barcelona: Paidós.

Koselleck, R. (2012). Historia de conceptos. Estudios sobre semántica y pragmática del lenguaje político y social (L. Fernández Torres, Trad.). Madrid, MD: Trotta.

Krutwig, F. (2006). Vasconia. Estudio dialéctico de una nacionalidad. Iruñea: Astero.

Lazzarato, M. (2020). Signos y máquinas. El capitalismo y producción de subjetividad. Madrid: Enclave.

Letamendia, F. (1994). Historia del Nacionalismo y de ETA. Tomo 1. San Sebastián: $R \& B$. 
Löwy, M., Varikas, E. (2007). La crítica al progreso en Adorno. En J. Holloway, F. Matamoros, S. Tischler (comps.), Negatividad y revolución, Theodor Adorno y la política (pp. 95-109). Buenos Aires: Herramienta.

Losurdo, D. (2019). El marxismo occidental. Cómo nació, cómo murió y cómo puede resucitar. Madrid: Trotta.

Le Breton, D. (1999). Antropología del dolor. Barcelona: Seix Barral.

Mainer, J. C. (2015). Letras e ideas bajo (y contra) el franquismo. En J. Casanova (ed.). Cuarenta años con Franco (pp. 229-266). Barcelona: Crítica.

Majuelo, E. (2020). El historiador ante el pasado vasco (no tan) reciente. Segle XX. Revista catalana d'historia, 13, pp. 283-296.

Marcilhacy, D. (2014). La Hispanidad bajo el franquismo. El americanismo al servicio de un proyecto nacionalista. En S. Michonneau, X. M. Núñez-Seixas (ed.), Imaginarios y representaciones de España durante el franquismo (pp. 73-102). Madrid: Casa de Velázquez.

Martín, F. N. (2017). Las dos filosofías de la historia de Adorno. Rev Cien Cult, 38, pp. 33-56. https://doi.org/10.5093/rhp2017a4

Martín, F. N. (2016). Valencias de la dialéctica negativa. Totalidad antagónica y posibilidad de emancipación sin totalidad. Revista de Filosofía, 2, pp. 187-210. https://doi.org/10.5209/RESF.53950

McAdam, D. (1998). Orígenes conceptuales, problemas actuales, direcciones futuras. En P. Ibarra, T. Benjamín (coord.), Los movimientos sociales. Transformaciones políticas y cambio cultural (pp. 89-110). Madrid: Trotta.

Mees, L. (1990). El nacionalismo vasco entre 1903 y 1923. Vasconia: Cuadernos de historia-geografía, 17, pp. 115-139.

Mees, L. (1992). Nacionalismo vasco. Movimiento obrero y cuestión social. Bilbao: SAF.

Mees, L. (2004). Politics, economy, or culture? The rise and development of Basque nationalism in the light of social movement theory. Theory and Society, 33, pp. 311-331. https://doi.org/10.1023/B:RYSO.0000038602.33658.92 
Mees, L. (2019). The Basque Contention. Ethnicity, Politics, Violence. Oxon: Routledge. https://doi.org/10.4324/9780429262586

Montero, M. (2018). El sueño de la libertad. Mosaico vasco de los años del terror. Oviedo: Nobel.

Mota Zurdo, D. (2021). En manos del Tío Sam. ETA y Estados Unidos. Granada: Comares.

Odriozola, O. (2016). Erakunde bat baino gehiago. ETA herri mugimendu gisa (19581968). (Tesis inédita de doctorado). UPV/EHU Bilbao.

Ortzi (1975). Historia de Euskadi: el nacionalismo vasco y ETA. Francia: Ruedo Ibérico.

Hernández-Pacheco, J. (1992). Los límites de la razón. Estudios de filosofía alemana contemporánea. Madrid: Tecnos.

Hernández-Pacheco, J. (1996). Corrientes actuales de filosofía. La Escuela de Frankfurt. La Filosofía Hermenéutica. Madrid: Tecnos.

Pérez-Agote, A. (2008). Las raíces sociales del nacionalismo vasco. Madrid: Centro de Investigaciones Sociológicas.

Pérez-Agote A. (2018). De la violencia política a la política convencional: los factores determinantes del proceso en Euskadi y su catalización. En M. Sepúlveda (ed.), Nación y nacionalismo en la España de las autonomías (pp. 327-352). Madrid: Agencia Estatal Boletín Oficial del Estado.

Pérez Soto, C. (2009). Dialéctica Negativa de Adorno, otro Hegel ausente. Santiago de Chile: Clinamen.

Pérez Soto, C. (2005). Sobre Hegel. Santiago de Chile: Palinodia.

Rigby, S. (2011). Historia, discurso y el paradigma postsocial ¿una revolución en Historiografía? Anales de historia antigua, medieval y moderna, 43, pp. 95-114. http://revistascientificas.filo.uba.ar/index.php/analesHAMM/article/view/2598

Rivera, A. (2018). La construcción del nosotros vasco y su influencia en la violencia terrorista. En Rivera, A., Mateo, E, (Ed.), Verdaderos creyentes. Pensamiento sectario, radicalización y violencia (pp. 41-59). Madrid: Catarata. 
Rivera, A. (2020). Una historia reciente del País Vasco con ETA dentro. Segle XX. Revista catalana d'historia, 13, pp. 297-309.

Rivas, A. (1998). El análisis de marcos: una metodología para el estudio de los movimientos sociales. En P. Ibarra, T. Benjamín (coords.), Los movimientos sociales. Transformaciones políticas y cambio cultural (pp. 181-218). Madrid: Trotta.

Rose, G. (1978). The Melancholy Science. An Introduction to the Thought of Theodor W. Adorno. London: The Macmillan Press. https://doi.org/10.1007/978-1-34915985-7

Sánchez-Cuenca, I. (2001). ETA contra el Estado. Barcelona: Tusquets.

Saz, I. (2003). España contra España: los nacionalismos franquistas. Madrid: Marcial Pons.

Schwarzböck, S. (2008). Adorno y lo político. Buenos Aíres: Prometeo.

Stone, A. (2014). Adorno, Hegel, and Dialectic. British Journal for the History of Philosophy, 22, pp. 1118-1141. https://doi.org/10.1080/09608788.2014.9522 64

Sullivan, J. (1988). El nacionalismo vasco radical. Madrid: Alianza.

Tarrow, S. (1997). El poder en movimiento. Movimientos sociales, acción colectiva y política. Madrid: Alianza.

Tejerina, B. (2015). Nacionalismo, violencia y movilización social en el País Vasco. Factores y Mecanismos del auge y declive de ETA. Papeles del CEIC, 3, pp. 1-19. https://doi.org/10.1387/pceic.15159

Tischler, S. (2007). Adorno: Sujeto, fetichismo político y lucha de clases. En J. Holloway, F. Matamoros, S. Tischler (comps.), Negatividad y revolución, Theodor Adorno y la política (pp. 111-128). Buenos Aires: Herramienta.

Tischler, S., García Vela, A.G. (2017). Teoría crítica y nuevas interpretaciones sobre la emancipación. Tla-Melaua, 42, pp. 186-207. https://doi.org/10.32399/ rtla.11.42.287 
Uriarte, T. (1998). El tratamiento del periodístico de ETA bajo el franquismo 19641975. Bilbao: Tesis Doctoral, UPV/EHU.

Verano, L. (2019). Dialéctica Negativa en Merleau-Ponty. Kriterion, 142, pp. 127142. https://doi.org/10.1590/0100-512×2019n14207lv

Watson, C. (2007). Basque nationalism and political violence: The ideological and intellectual origins of ETA. Reno: Center of Basque Studies.

Wellmer, A. (1993), Sobre la dialéctica de modernidad y posmodernidad, Madrid: Visor.

Žižek, S. (2001). Repetir Lenin. M. Malo de Molina Bodelón y R. Sánchez Cedillo, trad. Madrid: Akal, 2001.

Žižek, S. (2003). El sublime objeto de la ideología. Argentina: Siglo XXI.

Zulaika, J. (1990). Violencia Vasca. Metáfora y Sacramento. Madrid: Nerea.

Zulaika, J. (1991). Reyes, políticos, terroristas: la función ritual de ETA en relación al nacionalismo vasco. Revista de antropología social, 0, pp. 217-230.

Zulaika, J. (2007). Polvo de ETA. Irun: Alberdania. 